\title{
Methane Leaks from North American Natural Gas Systems
}

\section{Citation}

Brandt, A. R., G. A. Heath, E. A. Kort, F. O'Sullivan, G. Petron, S. M. Jordaan, P. Tans, et al. 2014. "Methane Leaks from North American Natural Gas Systems." Science 343 (6172) (February 13): 733-735. doi:10.1126/science.1247045.

\section{Published Version}

doi:10.1126/science. 1247045

\section{Permanent link}

http://nrs.harvard.edu/urn-3:HUL.InstRepos:30761876

\section{Terms of Use}

This article was downloaded from Harvard University's DASH repository, and is made available under the terms and conditions applicable to Open Access Policy Articles, as set forth at http:// nrs.harvard.edu/urn-3:HUL.InstRepos:dash.current.terms-of-use\#OAP

\section{Share Your Story}

The Harvard community has made this article openly available.

Please share how this access benefits you. Submit a story.

Accessibility 
Methane leakage from North American natural gas systems: Sources, uncertainties, and policy implications

Authors: A.R. Brandt, ${ }^{1 *}$ G.A. Heath, ${ }^{2}$ E.A. Kort, ${ }^{3}$ F. O’Sullivan, ${ }^{4}$ G. Pétron, ${ }^{5}$ S.M. Jordaan, ${ }^{6,7}$ P. Tans, ${ }^{5}$ J. Wilcox, ${ }^{1}$ A. Gopstein, ${ }^{8 \dagger}$ D. Arent, ${ }^{2,9}$ S. Wofsy, ${ }^{10}$ N. J.Brown, ${ }^{11}$ R. Bradley, ${ }^{12}$ G.D. Stucky ${ }^{13}$ D. Eardley, ${ }^{14}$ A. Patrinos, ${ }^{15}$ R. Harriss ${ }^{16}$

\section{Affiliations:}

${ }^{1}$ Department of Energy Resources Engineering, Stanford University, Stanford CA

${ }^{2}$ National Renewable Energy Laboratory (NREL), Golden CO

${ }^{3}$ Department of Atmospheric, Oceanic and Space Sciences, University of Michigan, Ann Arbor, MI.

${ }^{4}$ MIT Energy Initiative, Massachusetts Institute of Technology, Cambridge MA

${ }^{5}$ Climate Modeling and Diagnostics Laboratory, National Oceanic and Atmospheric Administration, Boulder $\mathrm{CO}$

${ }^{6}$ Department of Political Science, University of Calgary, Calgary AB.

${ }^{7}$ Electric Power Research Institute (EPRI), Palo Alto CA

${ }^{8}$ United States Department of State, Bureau of Energy Resources

${ }^{9}$ Joint Institute for Strategic Energy Analysis (JISEA), Golden CO

${ }^{10}$ Department of Atmospheric and Environmental Sciences, Harvard University

${ }^{11}$ Lawrence Berkeley National Laboratory, Environmental Energy Technologies Division

${ }^{12}$ Independent consultant

${ }^{13}$ Department of Chemistry and Biochemistry, Materials Department, University of California, Santa Barbara

${ }^{14}$ Kavli Institute for Theoretical Physics, UC Santa Barbara

${ }^{15}$ New York University, Center for Urban Science and Progress

${ }^{16}$ Environmental Defense Fund, Boulder, CO

* Correspondence to: abrandt@stanford.edu

$\dagger$ Mr. Gopstein was a special resource to the study team and is not responsible for the final content of this report. The views here do not necessarily represent the views of the United States Department of State.

\section{One Sentence Summary:}

Multiple scientific studies suggest that methane emissions from natural gas systems could be larger than estimated in official inventories, with implications for the use of natural gas in sustainable energy systems. 


\section{Main Text:}

Natural gas emits less carbon dioxide during combustion than other fossil fuels and can be flexibly used in a variety of industries. This makes natural gas (NG) a potential "bridge fuel" during the transition to a decarbonized energy system. However, due to the high global warming potential (GWP) of methane $\left(\mathrm{CH}_{4}\right)$, climate benefits from $\mathrm{NG}$ depend on system leakage rates.

Several recent estimates of leakage rates have challenged the benefits of fuel switching from coal to NG, a large near-term greenhouse gas (GHG) reduction opportunity (1-3). Policymakers require improved understanding of the leakage rates from NG systems. To this end, we review twenty years of scientific and technical literature on NG emissions. This study presents a first effort to systematically compare emissions estimates at scales ranging from devices $(\mathrm{kg} / \mathrm{y})$ to continent-wide atmospheric studies $(\mathrm{Tg} / \mathrm{y})$.

We first present results from "top-down" studies which measure airborne methane concentrations. We then discuss "bottom-up" studies, which measure device- and facilitylevel leakage rates. We explore differences between study results, and discuss attribution of emissions to natural gas systems. Lastly, we examine implications for GHG emissions policies.

Atmospheric studies employ aircraft $(1,4-7)$, tower $(3,5)$ and ground $(3,6-9)$ gas sampling, as well as remote sensing $(6,10,11)$. All such studies observe atmospheric concentrations, and must infer fluxes by accounting for atmospheric transport. Inference can be made using tracer-tracer correlations $(2,3,6,9,11,12)$, mass-balance $(1,13)$, and atmospheric modeling and inversion methods $(4,5,7,14)$. Strengths and weaknesses exist with each approach (see SI).

Figure 1 compiles published estimates of $\mathrm{CH}_{4}$ leakage at all scales. It includes all known studies which a) performed measurements of emissions at some scale, and b) compared these measurements to inventories or established emissions factors. The ratio of observed emissions to the comparable emissions inventory is plotted on the $\mathrm{x}$-axis, such that ratios $>1$ imply excess emissions observed relative to those expected.

Figure 1 plots estimated $\mathrm{CH}_{4}$ emissions from atmospheric studies above $10^{10} \mathrm{gCH}_{4} / \mathrm{y}$. We include all atmospheric studies of $\mathrm{CH}_{4}$ emissions - not just those that focus on $\mathrm{NG}$ - so as to bound emissions from NG. Across years, scales, and methods, these studies systematically find larger $\mathrm{CH}_{4}$ emissions than predicted by inventories (ratios generally $>1)$. Smaller-scale studies focusing on $\mathrm{NG}$ producing $(1-3,8)$ and consuming regions $(2$, $6,9-11,14$ ) find larger excess $\mathrm{CH}_{4}$ emissions than national-level studies. This trend may be due to averaging effects of continental-scale atmospheric processes, or due to regional atmospheric studies focusing on areas with air quality problems, such as wintertime ozone $(1,3)$.

To facilitate comparison, Figure 1(b) normalizes all atmospheric studies to a multiple of current EPA GHG inventory emissions estimates (see SI). After normalization, numerous measurements at national scale $\left(>10^{12} \mathrm{gCH}_{4} / \mathrm{y}\right)$ suggest emissions $\sim 1.5$ times those reported in the EPA GHG inventory $(\mathrm{GHGI})(4,5,7,8,14)$. 
Why might emissions inventories be under-predicting emissions? Current sampling-based inventory methods rely on a set of key assumptions: a) samples used to generate device emissions factors (EFs) are drawn from the same population whose emissions are being estimated; b) samples are of sufficient size to characterize the population, given heterogeneities in technologies and managerial practice; c) leakage processes are not dominated by outlier events; and d) that operations and device count data are known with reasonable certainty. Current methods do not satisfy these assumptions.

First, devices sampled are not likely to be representative of current technologies and practices (18). Production techniques are being applied at scales (e.g., hydraulic fracturing and horizontal drilling) that were unknown during EPA studies (18). Second, measurements for generating EFs are expensive, limiting sample sizes. Many EPA EFs have confidence intervals exceeding $100 \%$ relative error (19). If there is no consistent bias, wide confidence intervals can be mitigated by stratified sampling (20). However, there are reasons to suspect sampling bias in EFs: sampling occurred only at cooperating facilities, leading to possible self-selection bias.

Third, if emissions distributions have "heavy tails" (e.g., more high emissions sources than would be expected in a normal distribution), small samples can miss highconsequence emissions sources. Empirical evidence suggests that emissions rates are, in fact, extremely heterogeneous: emissions volumes have been shown to be dominated by a small fraction of measured sources at well sites $(21,22)$, gas processing plants $(23-25)$, co-produced liquids storage tanks (26), and transmission compressor stations $(18,27)$. For example, a study which measured $\sim 75,000$ points at gas processing plants found that $\sim 60 \%$ of the total leak volume came from $0.01 \%$ of sources $(28)$. Heterogeneity was also recently observed in near-surface $\mathrm{CH}_{4}$ concentrations above distribution systems (29).

Lastly, data on operations and device counts used in inventories are contradictory, incomplete, and of unknown representativeness $(30,31)$. These data limitations should improve with increased data reporting requirements recently enacted by EPA.

To facilitate comparison with atmospheric studies, Figure 1(a) (below $10^{9} \mathrm{gCH}_{4} / \mathrm{y}$ ) plots result from bottom-up studies where measurements were directly compared by study authors to EFs. Note that EFs were found to underestimate emissions on the balance, and that observed emissions ratios are much more erratic than observed atmospheric ratios.

A key challenge is attribution of atmospheric observations to sources. Isotopic analysis $(6,10)$ and prevalence signatures of non- $\mathrm{CH}_{4}$ hydrocarbons $(3,5-7)$ can be used to attribute emissions to fossil sources rather than biogenic sources. Evidence from regional studies suggests that fossil $\mathrm{CH}_{4}$ emissions are larger than expected $(3,5,6,8,10)$, while national-scale evidence favors a mix of biogenic and fossil sources (5). Atmospheric studies that control for biogenic $\mathrm{CH}_{4}$ sources $(1,2,6)$ depend on biogenic source estimation methods. One study suggests possible underestimation of ruminant emissions by $\sim 8 \mathrm{TgCH}_{4} / \mathrm{y}(5)$.

Natural seeps of hydrocarbons could confound attribution, as they have fossil isotopic and alkane signatures $(2,3,5)$. Current seepage estimates suggest that geologic sources could contribute to excess $\mathrm{CH}_{4}$ at rates of $\sim 2 \mathrm{Tg} \mathrm{CH}_{4} / \mathrm{y}(33,34)$. Attribution to liquid and gaseous hydrocarbon sources rather than coal has been established by atmospheric sampling in places with comparatively little coal-sector activity $(2,3,5,6,8)$. 
Attributing leakage to "natural gas" sources, as defined by EPA sector boundaries, is more challenging. Alkane fingerprints may allow attribution to oil-associated $\mathrm{NG}(8)$, although gas processing changes gas composition, which may complicate efforts to pinpoint leakage sources. Within the NG sector, geographic co-location (of what???) or isolating wind directions $(2,3,6)$ can attribute emissions to broad operation classes. Attributing emissions more specifically requires assumptions about gas composition that introduce significant uncertainty $(2,3,12)$.

Does current evidence suggest possible sources within the NG sector? Figure 2 plots results from a thought experiment which estimates magnitudes of possible sources within the NG sector, as well as sources that could be mistaken for NG emissions due to chemical and isotopic signatures. Overall possible excess $\mathrm{CH}_{4}$ from all sources (7-21 $\mathrm{Tg} / \mathrm{y}$ ) is estimated using Figure 1(b) result of $\sim 1.5+/-0.25$ times EPA GHGI estimates.

Excess emissions scenarios for upstream, downstream, and petroleum sector sources apply observed leakage rates from the literature that are higher than EPA estimates $(1,2$, 6). The frequency of such high emitting practices is unknown, so illustrative prevalence scenarios are plotted: $1 \%, 10 \%$, or $25 \%$ of activity is represented by high emitters, while the remainder emit at EPA GHGI rates. Note that atmospheric estimates of high leakage rates $(1,2,6)$ are unlikely to be broadly representative of the NG industry, as emissions from the NG sector would exceed the entire observed excess atmospheric $\mathrm{CH}_{4}$.

More specific assessment of sources shows that hydraulic fracturing for NG is unlikely to be a dominant contributor to leakage. Also, some sources not included in the GHGI may contribute to excess emissions, including abandoned oil and gas wells, as well as geologic seeps (see SI).

Leakage scenarios shown in Figure 2 have implications for decision-making and policy. A key tool for environmental decision-making is life cycle assessment (LCA). Recent LCAs have estimated impacts from NG use in power generation and transport (see SI). LCA studies generally agree that replacing coal with natural gas has climate benefits (35). However, LCAs have relied heavily on EPA GHGI results. Updating these assessments with uncertainty ranges from Figure 2 (see SI) supports robust climate benefits from NG substitution for coal in the power sector over a 100 -year assessment period. Climate benefits from vehicle fuel substitution are uncertain (gasoline, light-duty) or improbable (diesel, heavy-duty).

This evidence illuminates opportunities and challenges in addressing natural gas leakage. Many technologies with lower designed leakage rates are economically profitable at moderate gas prices (36). Such technologies are being adopted or are required in forthcoming regulation (37) (e.g., reduced emissions completions).

The non-normal distribution of empirically observed emissions rates presents a significant opportunity for mitigation: such heterogeneity implies large benefits if scientists and engineers develop reliable remote methods for finding and fixing the small fraction of high-emitting devices.

This heterogeneity in emissions rates also implies that creating accurate statistical distributions of emissions magnitudes can be challenging for such a large and diverse industry. Therefore, policy solutions must be robust to likely continued uncertainty in 
emissions rates, and should not assume "typical" emissions rates apply to a given technology. Policies will be more successful if they encourage finding failed components with regular inspections (similar to successful efforts to reduce vehicular smog).

Better information and improved science would aid cost effective policy responses. Improved atmospheric measurements can provide a check on inventories. More focused atmospheric studies can pinpoint leakage sources for further investigation. Equipment measurements can be performed at facilities of a variety of designs, vintages, and management practices to find low-cost mitigation options. One study in this regard is currently underway (38), but more work is required.

In summary, the current state of knowledge suggests that: a) there is a consistent signal of excess $\mathrm{CH}_{4}$ emissions compared to official inventories; b) evidence suggests excess emissions from fossil sources, of which the NG sector is likely to be a large contributor; c) numerous independent experiments suggest that a small number of "super-emitters" could be responsible for a large fraction of leakage; d) system-wide leakage is unlikely to be large enough to disfavor coal-to-NG substitution.

If natural gas fuel switching is to be a "bridge" to a sustainable energy future, it is a bridge that must be traversed carefully: diligence will be required to ensure that leakage rates are low enough to achieve sustainability goals.

Acknowledgments: This study was funded by Novim and the George B. Mitchell Foundation. The authors note the recent passing of George Mitchell, who pioneered hydraulic fracturing. Mr. Mitchell strongly believed that this technology should be pursued in ecologically sound ways. C. Brown and D. Heppe of the Environmental Capital Group provided reference gathering assistance. We also acknowledge the support of the Joint Institute for Strategic Energy Analysis (JISEA). JISEA is operated by the Alliance for Sustainable Energy, LLC, on behalf of the U.S. Department of Energy's National Renewable Energy Laboratory, the University of Colorado-Boulder, the Colorado School of Mines, the Colorado State University, the Massachusetts Institute of Technology, and Stanford University.

\section{References and Notes:}

1. A. Karion et al., Geophys. Res. Lett. 40, 4393 (2013).

2. J. Peischl et al., J. Geophys. Res. 118, 4974 (2013).

3. G. Petron et al., J. Geophys. Res. 117, D04304 (2012).

4. $\quad$ E. A. Kort et al., Geophys. Res. Lett. 35, 1 (2008).

5. S. M. Miller et al., Proc. Natl. Acad. Sci. U.S.A., In review (2013).

6. P. O. Wennberg et al., Environ. Sci. Technol. 46, 9282 (2012).

7. Y. Xiao et al., J. Geophys. Res. 113, 1 (2008).

8. A. S. Katzenstein, L. A. Doezema, I. J. Simpson, D. R. Blake, F. S. Rowland, Proc. Natl. Acad. Sci. U.S.A. 100, 11975 (October 14, 2003, 2003).

9. $\quad$ Y.-K. Hsu et al., Atmos. Environ. 44, 1 (2010).

10. A. Townsend-Small, S. C. Tyler, D. E. Pataki, X. Xu, L. E. Christensen. J. Geophys. Res. 117, D07308 (2012). 
11. D. Wunch, P. O. Wennberg, G. C. Toon, G. Keppel-Aleks, Y. G. Yavin, Geophys. Res. Lett. 36, (2009).

12. M. A. Levi, J. Geophys. Res. 117, (2012).

13. K. L. Mays et al., Environ. Sci. Technol. 43, 7816 (2009).

14. G. W. Santoni et al., J. Geophys. Res. In review, (2013).

15. U.S. EPA, Greenhouse Gas Emissions Reporting from the Petroleum and Natural Gas Industry, Background Technical Support Document. (2010).

16. EPA/GRI, M. R. Harrison, L. M. Campbell, T. M. Shires, R. M. Cowgill, "Methane Emissions from the Natural Gas Industry, Volume 1: Executive Summary" (1996).

17. D. A. Kirchgessner, R. A. Lott, R. M. Cowgill, M. R. Harrison, T. M. Shires, Chemosphere 35, 1365 (1997, 1997).

18. M. R. Harrison et al., "Natural gas industry methane emissions factor improvement study" (URS Corportation and The University of Texas at Austin, Austin, TX, 2011).

19. EPA/GRI, H. K. E., L. M. Campbell, M. R. Harrison, "Methane Emissions from the Natural Gas Industry, Volume 8: Equipment Leaks" (1996).

20. EPA/GRI, H. J. Williamson, M. B. Hall, M. R. Harrison, "Methane Emissions from the Natural Gas Industry, Volume 4: Statistical Methodology" (1996).

21. Eastern Research Group, Sage Environmental Consulting, "City of Fort Worth Natural Gas Air Quality Study" (2011).

22. R. A. Alvarez, S. W. Pacala, J. J. Winebrake, W. L. Chameides, S. P. Proc. Natl. Acad. Sci. U.S.A., (April 9, 2012, 2012).

23. A. Chambers, "Optical measurement technology for fugitive emissions from upstream oil and gas facilities" (Alberta Research Council, Edmonton, AB, 2004).

24. A. Chambers, M. Strosher, T. Wootton, J. Moncrieff, P. McCready, DIAL Measurements of Fugitive Emissions from Natural Gas Plants and the Comparison with Emission Factor Estimates. (2006).

25. T. Trefiak, "Pilot study: Optical leak detection and measurement" (ConocoPhillips, 2006).

26. D. Picard, in Modern technolgies of detection and elimination of methane leakages from natural gas systems. (Akademgorodok, Russia, 2005).

27. J. Cormack, in Energy Management Workshop for Upstream and Midstream Operations: Increasing Revenue through Process Optimization \& Methane Emissions Reduction. (Global Methane Initiative, Calgary, Alberta Canada, 2007).

28. NGML, Clearstone, IES, "Cost-effective directed inspection and maintenance control opportunities at five gas processing plants and upstream gathering compressor stations and well sites" (U.S. EPA, Washington, DC, 2006).

29. N. Phillips et al., Environmental Pollution 173, 1 (2013).

30. U.S. EPA, "Inventory of U.S. Greenhouse Gas Emissions and Sinks: 1990-2011" (2013).

31. EPA, "EPA Needs to Improve Air Emissions Data for the Oil and Natural Gas Production Sector" (U.S. EPA, Office of Inspector General, Washington, D.C., 2013). 
32. U.S. EPA, "Inventory of U.S. Greenhouse Gas Emissions and Sinks: 1990-2011. Annex 3: Methodological descriptions for additional source or sink categories" (2013).

33. EPA, "Methane and nitrous oxide emissions from natural sources" (United States Environmental Protection Agency, Washington, D.C., 2010).

34. G. Etiope, K. Lassey, R. W. Klusman, E. Boschi, Reappraisal of the fossil methane budget and related emission from geologic sources. Geophys. Res. Lett. 35, (2008).

35. C. L. Weber, C. Clavin, Life Cycle Carbon Footprint of Shale Gas: Review of Evidence and Implications. Environ. Sci. Technol. 46, 5688 (2012, 2012).

36. S. Harvey, V. Gowrishankar, T. Singer, "Leaking Profits: The U.S. Oil and Gas Industry Can Reduce Pollution, Conserve Resources, and Make Money by Preventing Methane Waste" (Natural Resources Defense Council, 2012).

37. EPA, "40 CFR Parts 60 and 63: Oil and Natural Gas Sector: New Source Performance Standards and National Emission Standards for Hazardous Air Pollutants Reviews; Final Rule" (National Archives and Records Administration, 2012).

38. EDF, "Natural gas: EDF is fighting for tough rules and enforcement" (Environmental Defense Fund, 2013). 


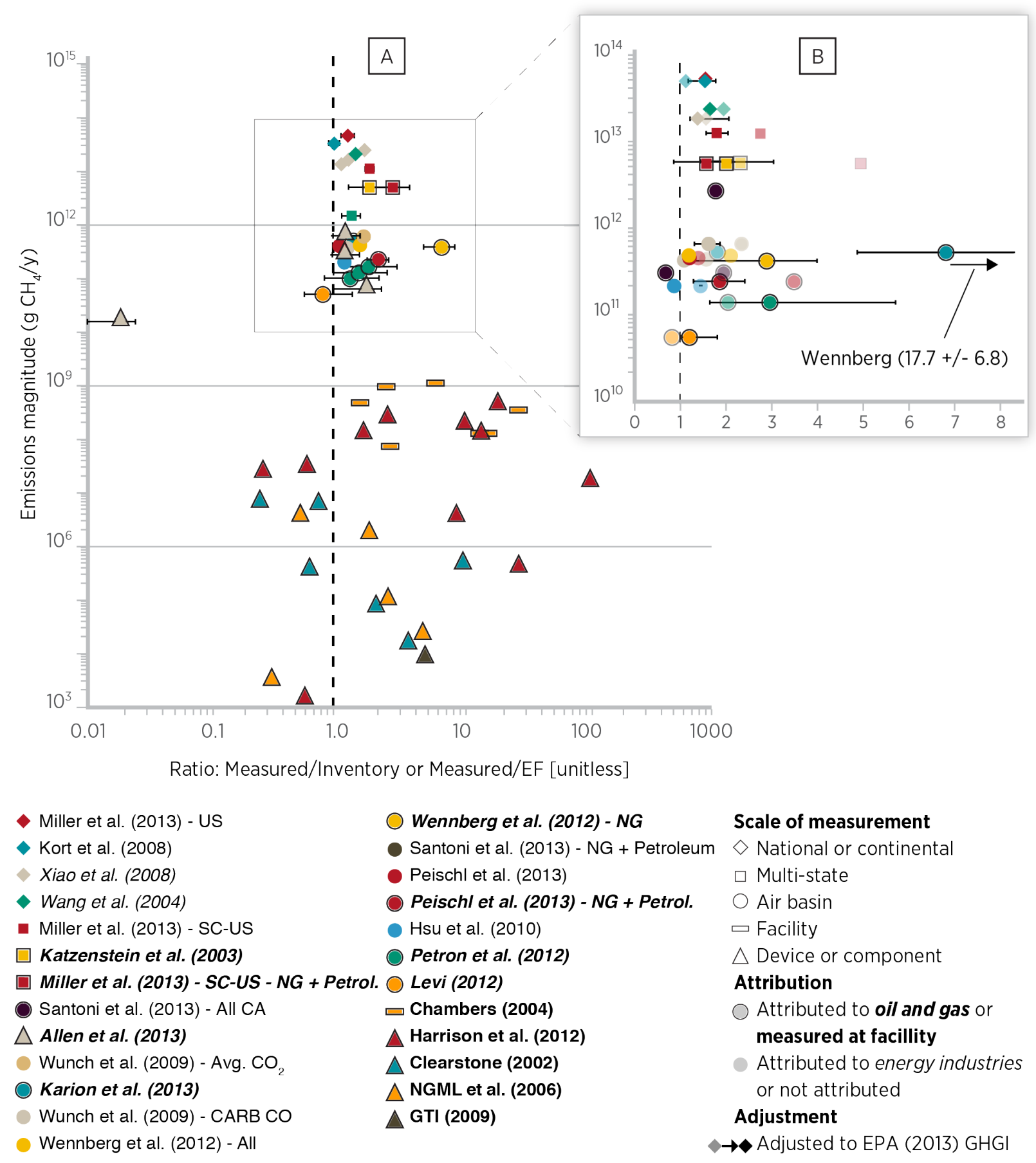

Figure 1. Ratio of measured emissions to inventory estimates for measurement-based studies of $\mathrm{CH}_{4} \mathrm{emissions}$ Consistent rightward-bias in ratio suggests common underestimation of gas emissions across scales. Atmospheric studies are included even if no NG-specific flux is estimated in order to establish excess $\mathrm{CH}_{4}$ budget. Frame (a), compares results to the emissions factor or inventory estimate chosen by each study author. Frame (b) compares results to a common denominator (EPA 2013 GHGI). The EPA GHGI is scaled to region of study (transparent $=$ pre-adjustment, solid $=$ post-adjustment). Definitions of error bar bounds vary between studies. (US = United States; $S C=$ South Central; O\&G $=$ oil and gas; avg = average; CARB = California Air Resources Board; NG = natural gas) 


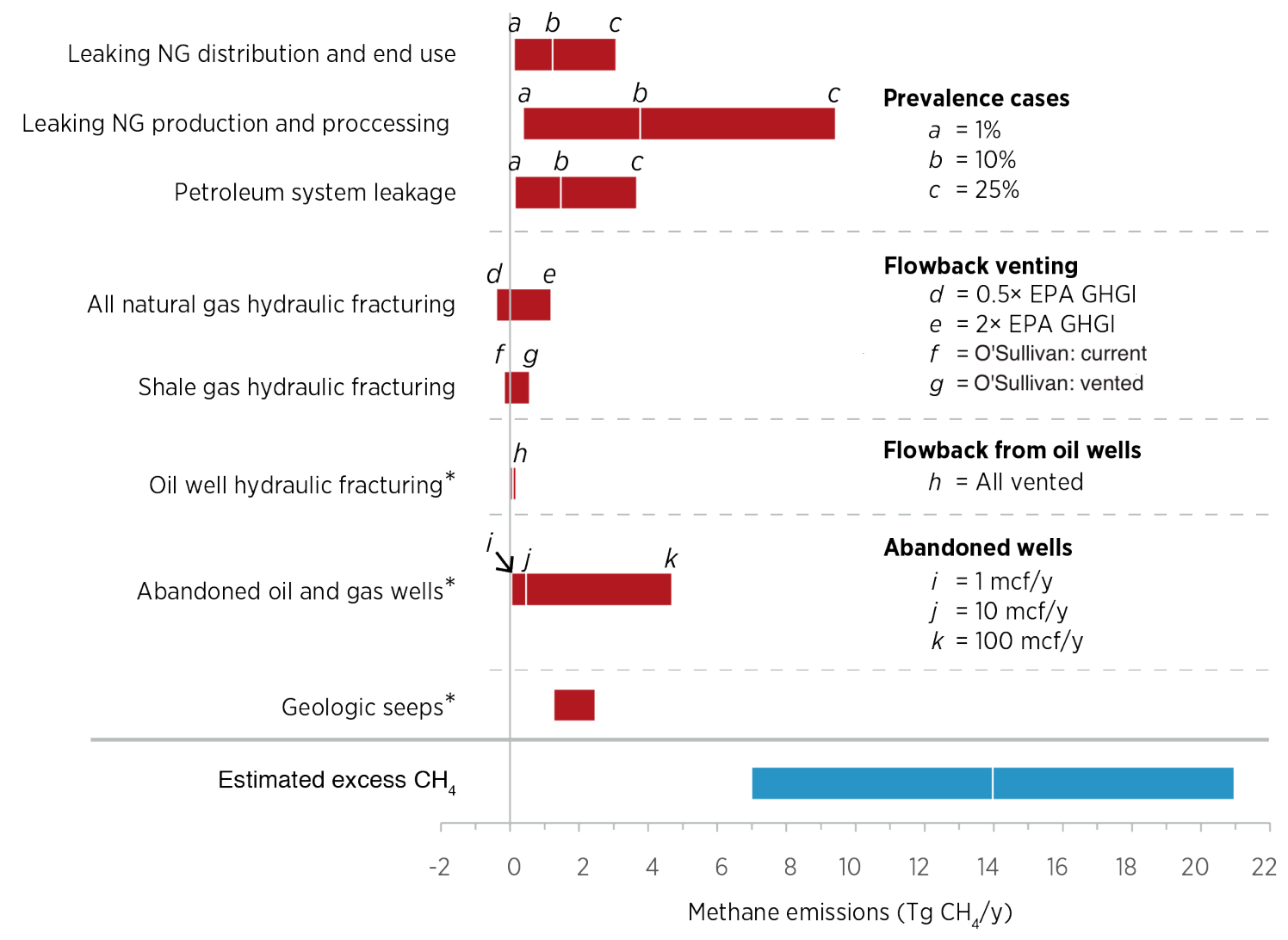

Figure 2. Exploration of potential emissions sources from the NG sector or confounding sectors. See SI for scenario construction. 


\title{
Science \\ \IAAAS
}

\section{Supplementary Materials for}

\section{Methane Leaks from North American Natural Gas Systems}

A. R. Brandt, * G. A. Heath, E. A. Kort, F. O’Sullivan, G. Pétron, S. M. Jordaan, P. Tans, J. Wilcox, A. M. Gopstein, D. Arent, S. Wofsy, N. J. Brown, R. Bradley, G. D. Stucky D. Eardley, R. Harriss

\author{
*Corresponding author. E-mail: abrandt@stanford.edu \\ Published 14 February 2014, Science 343, 733 (2014) \\ DOI: $10.1126 /$ science. 1247045
}

This PDF file includes

\author{
Materials and Methods \\ Supplementary Text \\ Figs. S1 to S3 \\ Tables S1 to S5 \\ References
}

Other Supplementary Material for this manuscript includes the following: (available at www.sciencemag.org/content/343/6172/733/supp1/DC1)

Data file S1.NG_leakage.xlsx: 
1\# Materials and Methods.................................................................................................. 2\#

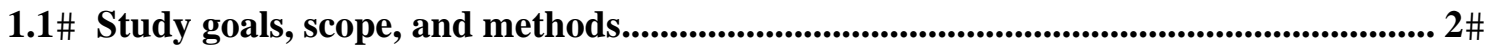

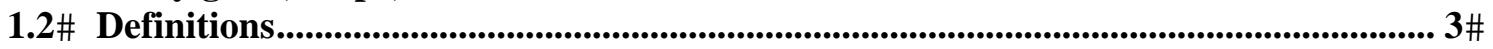

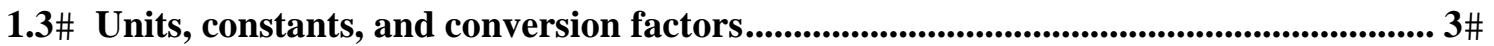

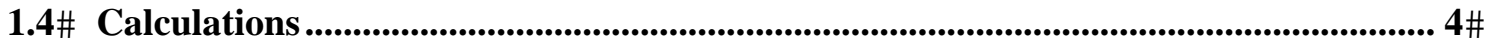

1.4.1\# First text chart: Comparison of measured emissions rates to inventories or emissions

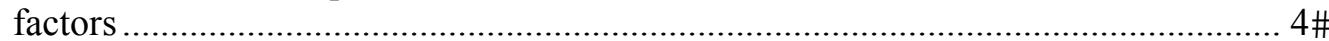

1.4.2\# The first text chart (inset): Adjustment of atmospheric estimates to scaled EPA

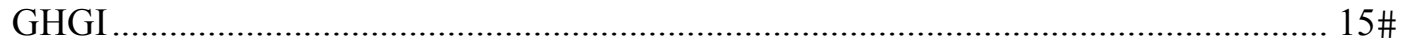

1.4.3\# The second text chart: Exploration of possible sources of excess $\mathrm{CH}_{4} \ldots \ldots \ldots \ldots \ldots \ldots . . . . .22 \#$

1.4.4\# Calculating leakage percentages associated with possible NG leakage .................... 29\#

2\# Supplementary text ................................................................................................. 30\#

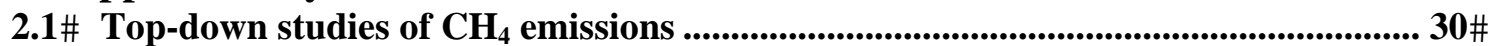

2.1.1\# Transport box models (mass balance models)................................................... 30\#

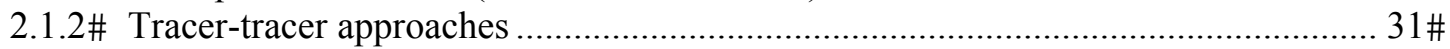

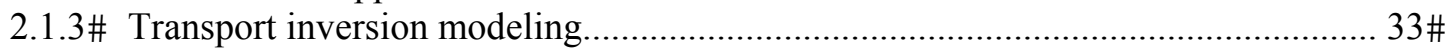

2.1.4\# Approaches for source attribution .................................................................. 34\#

2.1.5\# Uncertainty in top-down measurements ........................................................... 35\#

2.2\# Bottom-up methods: Inventories and emissions factors......................................... 39\#

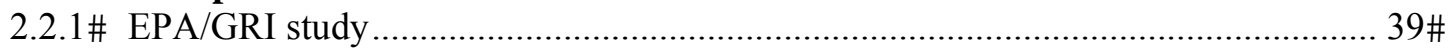

2.2.2\# Current EPA GHGI methodologies and results.................................................... 46\#

2.2.3\# Bottom-up studies performed since EPA/GRI 1996 ............................................. 47\#

2.3\# Alignment between bottom-up and top-down studies: Attribution and system

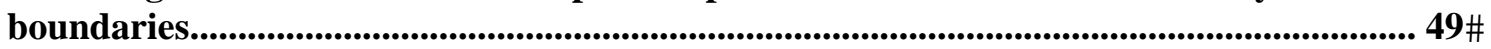

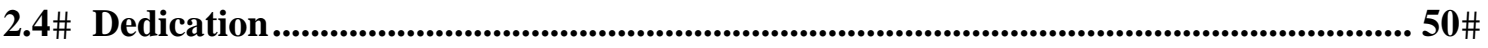

2.5\# Advisory and Financial Disclosures ........................................................................... 51\#

3\# Supplemental Figures .......................................................................................... 54\#

4\# $\quad$ References......................................................................................................57\# 


\section{Materials and Methods}

\subsection{Study goals, scope, and methods}

This study synthesizes the state of knowledge of leakage of gas from natural gas (NG) systems in North America. Gas leakage is a concern for greenhouse gas (GHG) emissions because the primary component of NG is methane $\left(\mathrm{CH}_{4}\right)$, which has a significant global warming potential (GWP). Implications of this state of knowledge for policy are also discussed. More than 200 technical publications were reviewed for this study.

The scientific subquestions we examine include the following:

1. What do we know about device- or facility-level leakage rates? (e.g., what do we know about NG leakage from hydraulic fracturing?)

2. What uncertainties exist in building inventories of $\mathrm{CH}_{4}$ emissions?

3. What do top-down atmospheric observations of $\mathrm{CH}_{4}$ concentrations at various scales tell us about NG leakage rates?

4. What are the key drivers behind disparity between top-down and bottom-up estimates of leakage?

5. Can we specifically define and estimate excess emissions to sources within the NG sector?

The policy subquestions we address include the following:

1. What are the policy implications of the current state of scientific understanding of methane emissions from the petroleum sector and, specifically, NG?

2. Does methane leakage affect the "cutoffs" for appropriate NG fuel-switching options for climate mitigation? When is coal substitution favorable? When is diesel or gasoline substitution favorable?

This study assesses all NG segments where $\mathrm{CH}_{4}$ is emitted to the atmosphere. We assess fugitive emissions (unintentional) and vented emissions (intentional), both routine and nonroutine. We also examine the extent to which other $\mathrm{CH}_{4}$ sources (e.g., petroleum operations and solid waste facilities) may interfere with attribution of $\mathrm{CH}_{4}$ concentrations to NG systems.

All types of NG are analyzed. To the extent that coproduced, oil-associated gas (associated gas) supplies $\sim 20 \%$ of U.S. gross NG withdrawals (30), we examine gas coproduction at oil fields. We pay particular attention to changes in emission rates resulting from shifts from conventional resources to shale gas. We focus primarily on the U.S. gas system, with some studies including data on Canadian emissions. 


\subsection{Definitions}

Bottom-up studies: These studies use direct measurements of emissions of gas at the device or facility level. Also, they refer to emissions inventories and life-cycle assessment (LCA) studies based on bottom-up data.

Top-down studies: Studies that use measurements of emissions at facility to national scales, typically taken at a location remote from individual pieces of equipment, such that atmospheric effects integrate emissions from multiple devices. Such studies require interpretation or modeling to assign or attribute emissions to sources such as the NG system. Facilities can be considered measurable via both top-down and bottom-up approaches, as estimates for facility level emissions can be made through exhaustive bottom-up measurement of all emission sources in a facility or via down-wind atmospheric studies by using tracer-based or plume transect approaches.

Hydrocarbons: Liquid and gaseous fossil fuels comprised of (primarily) $\mathrm{C}$ and $\mathrm{H}$. These fluids are produced from hydrocarbon production wells, generally in conjunction with each other (e.g., "gas wells" generally produce some liquid hydrocarbons, while "oil wells" produce some gaseous hydrocarbons). Unless specifically noted, coal is not included in the current study.

\subsection{Units, constants, and conversion factors}

The studies examined in this review report emissions in a variety of units. In order to allow comparisons between studies, all estimates are converted to grams $(\mathrm{g})$ of $\mathrm{CH}_{4}$ emitted (e.g., $\mathrm{Tg} \mathrm{CH}_{4} /$ year). In some cases, results will be discussed in "field units" [e.g., standard cubic foot (SCF)]. Standard conditions in this report are defined as 14.73 psia and $60^{\circ} \mathrm{F}$, resulting in 1.198 moles of ideal gas per SCF.

For clarity, the meaning of field units and their form used in this study (main text, SI) are listed in Table S1. Conversion factors used in converting field units to $\mathrm{g}$ of $\mathrm{CH}_{4}$ are taken from EPA average compositions, listed in Table S2, Table S3, and Table S4.

Table S1. Field units from NG industry

\begin{tabular}{lll}
\hline Unit & Meaning & Numerical defn. \\
\hline MSCF & Thousand standard cubic feet & $10^{3} \mathrm{ft}^{3}$ at standard conditions \\
MMSCF & Million standard cubic feet & $10^{6} \mathrm{ft}^{3}$ at standard conditions \\
BCF & Billion standard cubic feet & $10^{9} \mathrm{ft}^{3}$ at standard conditions \\
TCF & Trillion standard cubic feet & $10^{12} \mathrm{ft}^{3}$ at standard conditions \\
\hline
\end{tabular}


Table S2. Conversion factors and constants used

\begin{tabular}{lll}
\hline Quantity & Value & Units \\
\hline Moles per SCF (ideal gas) & 1.1980 & $\mathrm{~mol} / \mathrm{SCF}$ \\
Molecular weight $\mathrm{CH}_{4}$ & 16 & $\mathrm{~g} / \mathrm{mol}$ \\
Mass of $\mathrm{CH}_{4}$ per $\mathrm{SCF} \mathrm{CH}_{4}$ & 19.17 & $\mathrm{~g} \mathrm{CH} / \mathrm{SCF} \mathrm{CH}_{4}$ \\
$\mathrm{SCF}$ per m & & $\mathrm{SCF} / \mathrm{m}^{3}$ \\
\hline
\end{tabular}

Table S3. EPA gas composition by NG production stage. Source: EPA 2011 inventory (17), annex 3, table A-128, and pp. A178-A179.

\begin{tabular}{|c|c|c|}
\hline Stage - Quantity & Value & Unit \\
\hline Production & 0.841 & $\mathrm{~mol} \mathrm{CH}_{4} / \mathrm{mol}_{\text {gas }}$ \\
\hline Processing & 0.870 & $\mathrm{~mol} \mathrm{CH}_{4} / \mathrm{mol}$ gas \\
\hline Transmission & 0.934 & $\mathrm{~mol} \mathrm{CH}_{4} / \mathrm{mol}$ gas \\
\hline Distribution & 0.934 & $\mathrm{~mol} \mathrm{CH}_{4} / \mathrm{mol}_{\text {gas }}$ \\
\hline
\end{tabular}

Table S4. EPA mass-to-volume conversion factors. Source: computed from above.

\begin{tabular}{lll}
\hline Stage - Quantity & Value & Unit \\
\hline Production & 62.03 & MMSCF NG/Gg CH \\
Processing & 59.96 & MMSCF NG/Gg CH \\
Transmission & 55.85 & MMSCF NG/Gg CH \\
Distribution & 55.85 & MMSCF NG/Gg CH \\
\hline
\end{tabular}

\subsection{Calculations}

\subsubsection{First text chart: Comparison of measured emissions rates to inventories or emissions factors}

The first text chart compiles data from all available studies where a measured emissions rate from a given device, facility, air basin, or region, is compared to an inventory-based estimate or emissions factor (EF). The main part of the chart plots only the comparisons made by study authors themselves to the inventory or emissions factor that the authors deemed most comparable. We compute this comparison as a ratio of observed emissions over inventoried emissions (or over EF values) although not all authors express their own results using this ratio. The inventory or emissions factor used for comparison differs between studies (e.g., California Air Resources Board inventory, as compared to EPA GHG inventory, etc.). Study results are not corrected or modified in the main part of the first text chart to account for interpretation or attribution errors made by the study authors. We note instances where challenges in interpretation or comparison exist with a given study. 
Measurements in these studies occurred across orders of magnitude of spatial scale (compressor seals to continents) and temporal scale (seconds to decades). We display this variability on the $y$ axis of the first text chart by plotting results by measured rate of emissions.

The following data were collected for each study:

- Author;

- Institution;

- Study region or boundary;

- Location of study;

- Measurement methods;

- Modeling methods;

- Data vintage;

- Noted limitations;

- Natural gas stage(s) studied;

- Type(s) of NG;

- Gas species measured;

- Units reported;

- Emissions mechanism(s) studied (if applicable);

- Measured quantity of emissions (with specified high and low ranges). In studies where multiple cases were constructed, each case was recorded with its appropriate ranges;

- Type of uncertainty range, if specified (e.g., $95 \%$ confidence interval);

- Other notes;

- Emissions estimate from inventory or EF approach that was used for comparison by study author;

- Notes on comparable inventory or EF figure.

Some studies include multiple cases. Cases can differ based on the region included, the sources included, or the assumptions underlying the results.. All cases examined were included as long as they met the study criteria listed in the previous section.

These data are recorded in Data File S1 in the "Methods comparison" and "Calc - Figure 1 - Main" worksheets.

For each study and case, we compute the ratio of measured emissions to the inventory or emissions factor that the author uses for comparison (see first chart in the main text). This ratio is plotted as the $x$-axis variable of the first chart for each study. If uncertainty ranges are available for both the measured emissions and the comparable inventory or EF, three ratios are constructed:

- Central ratio: central estimate from study is compared to central estimate from the comparable inventory or EF.

- High ratio: High estimate from study is compared to low estimate of the inventory or EF. 
- Low ratio: Low emissions result from study is compared to high emissions estimate of comparable inventory or EF.

If comparable inventory or EF estimate is presented as a point value, than this single point value is used as the denominator of all three ratios. If both the measured value and the comparable inventory or EF are presented as point estimates, then a simple point estimate of the ratio is computed.

\subsubsection{Sources of data and calculation methods for each study}

For each study, we outline the source of data and any calculation methods or assumptions below, as required to generate the results shown in first text chart.

These ratios are plotted in the main part of the first chart where the $y$-axis plots the scale of the measured emissions magnitude, in $\mathrm{g} \mathrm{CH}_{4}$ per year. Because the scale of measured emissions rates ranges from $\mathrm{kg}$ to $\mathrm{Tg}$, a logarithmic scale is used. Similarly, a logarithmic scale is used on the $x$ axis because of very large variation in ratios (0.01 to 1000). These data and calculations are recorded in Data File S1 in the "Calc - Figure 1 - Main" worksheet.

\section{Miller et al.}

Miller et al. (6) create three cases that we include in the first text chart. See below for discussion of the experimental and analytical methods used in Miller et al.

Case 1 estimates emissions for all sources across the entire United States. For this case, Miller et al. estimate emissions of $33.4( \pm 1.5) \mathrm{TgC}$ as $\mathrm{CH}_{4} /$ year, as gathered from figure 1 [BPO1] in the original paper (and author communication). This is equivalent to to 45 $( \pm 1.9) \mathrm{Tg} \mathrm{CH} /$ year. Miller et al. compare their emissions estimate to both the EPA GHG inventory (GHGI) and the EDGAR spatial emissions database for the time and region of interest. We only utilize the EPA estimate in this study. The comparable estimate from the EPA inventory is $22.1( \pm 2.9) \mathrm{Tg} \mathrm{CH}_{4} /$ year. This leads to a central estimate for the ratio of measured/estimated to be $1.5(+0.3,-0.23) \mathrm{g} / \mathrm{g}$.

Case 2 estimates emissions for the South-Central United States (SC-US). For this case, Miller et al. estimate emissions of $8.1( \pm 1) \mathrm{TgC}$ as $\mathrm{CH}_{4} /$ year, as gathered from article text (and author communication) in the original paper. This is equivalent to $11( \pm 1.3) \mathrm{Tg}$ $\mathrm{CH}_{4}$ /year. Miller et al. compare their emissions estimate to the EDGAR spatial emissions database for the region of interest. The comparable estimate from the EDGAR case is 3 $\mathrm{Tg} \mathrm{CH}_{4} /$ year. This leads to a central estimate for the ratio of measured/estimated to be 2.7 $(+0.3,-0.3) \mathrm{g} / \mathrm{g}$.

Case 3 estimates oil- and gas-related emissions for the South-Central United States (SCUS: Fossil). For this case, Miller et al. estimate emissions of $3.7( \pm 2) \mathrm{TgC}$ as $\mathrm{CH}_{4} /$ year, as gathered from article text (and author communication) in the original paper. This is 
equivalent to $4.9( \pm 2.6) \mathrm{Tg} \mathrm{CH}_{4} /$ year. Miller et al. compare their emissions estimate to the EDGAR spatial emissions database for the region of interest for oil and gas sources. The comparable estimate from the EDGAR case is $0.75 \mathrm{Tg} \mathrm{CH}_{4} /$ year. This leads to a central estimate for the ratio of measured/estimated to be $4.9( \pm 2.6) \mathrm{g} / \mathrm{g}$.

\section{Kort et al.}

Kort et al. (5) create one case that we include in the first text chart. See below for discussion of the methods used in Kort et al. The Kort et al. study estimates $\mathrm{CH}_{4}$ emissions for North America (United States and Canada). Kort et al. report emissions of $1.08( \pm 0.15) \mathrm{g} / \mathrm{g}$, measured as a multiple of EDGAR v3.2 estimates for the region. These results are gathered from $\mathrm{p} .4$ in the original source. The comparable estimate from EDGAR v3.2 is $30 \mathrm{TgC}$ as $\mathrm{CH}_{4} /$ year. This estimate is equivalent to $43.2( \pm 6) \mathrm{Tg}$ $\mathrm{CH}_{4} /$ year, given the EDGAR baseline emissions for the year of data collected.

It should be noted that due to the large variability in EDGAR emissions estimates, and between EDGAR and EPA baseline emissions estimates, the multiple of $1.08 \mathrm{~g} / \mathrm{g}$ found by Kort et al. with EDGAR 3.2, becomes significantly poorer agreement when compared to EDGAR v4.2 or recent EPA estimates. This is seen in the inset in the first text chart and is described below.

\section{Katzenstein et al.}

Katzenstein et al. (9) create one case that we include in the first text chart. See below for discussion of the methods used in Katzenstein et al. The Katzenstein et al. case estimates emissions for the South-Central United States, defined as Texas, Oklahoma, and Kansas. They report emissions of $4( \pm 1) \mathrm{Tg} \mathrm{CH}_{4} /$ year, as gathered from p. 11978 in the original source. Katzenstein et al. compare their emissions estimate to emissions from the U.S. oil and gas industries. The comparable estimate, implied by their assumptions, is $2.2 \pm 0.7 \mathrm{Tg}$ $\mathrm{CH}_{4} /$ year. This leads to a central estimate for the ratio of measured/estimated to be 2.3 $+1.8,-0.9 \mathrm{~g} / \mathrm{g}$.

Katzenstein et al. did not compute the ratio above, but instead they imply the comparison in text on p. 11978 of the original source (9). The article text leaves ambiguous whether their $\mathrm{CH}_{4}$ emissions estimate should be compared to NG emissions, $\mathrm{NG}$ and petroleum emissions, or all emissions in the region of interest. Our interpretation of the text suggests that Katzenstein et al. meant their result to be comparable to NG emissions from the region of interest.

Wang et al., cited in Xiao et al.

Wang et al. (13) create one case that we include in the first text chart. Xiao et al. cite an estimate from Wang et al. of emissions for the U.S. energy industries. They estimate emissions of $20 \mathrm{TgCH}_{4} /$ year, as gathered from paragraph 5 in Xiao et al (8). Xiao et al. 
compare the emissions estimate from Wang et al. to the EPA GHGI from 2007/2008 for the time and region of interest. The comparable emissions quantity is estimated by Xiao et al. to be $\sim 10 \mathrm{TgCH}_{4} /$ year (see Xiao et al. para. 5 and 40) (8). This leads to a central estimate for the ratio of measured/estimated emissions of $1.9 \mathrm{~g} / \mathrm{g}$.

The Wang et al. estimate for U.S. energy industry emissions is cited as a personal communication in Xiao et al. (8). The original source of the emissions estimate was not found in the Wang et al. paper. Therefore, it is likely that the regional result presented here was computed as part of the global analysis in the cited paper, but not originally published as a region-specific result.

\section{Xiao et al.}

Xiao et al. (8) create three cases that we include in the first text chart as a median case with high-low ranges. See below for discussion of the methods used in Xiao et al. Each case estimates emissions for total $\mathrm{CH}_{4}$ emissions from energy industries in the United States, using $\mathrm{C}_{2} \mathrm{H}_{6}$ emissions as modeled in their study. They report emissions of $2.4 \mathrm{Tg}$ $\mathrm{C}_{2} \mathrm{H}_{6}$ /year, which can be converted to three estimates of $\mathrm{CH}_{4}$ emissions using three $\mathrm{CH}_{4} / \mathrm{C}_{2} \mathrm{H}_{6}$ ratios presented in table 4 and paragraph 40 in the original source. We convert these emissions to $13.3,16.0$, and $24.0 \mathrm{Tg} \mathrm{CH}_{4} /$ year (see Data file $\mathrm{S} 1$ for details). Xiao et al. compare their emissions estimate to a round estimate of $\sim 10 \mathrm{Tg} \mathrm{CH}_{4} /$ year for the time and region of interest, using results for the year being modeled from two different EPA GHGIs. This leads to a central estimate for the ratio of measured/estimated emissions of $1.6(+0.9,-0.4) \mathrm{g} / \mathrm{g}$.

This study is an important piece of corroborating evidence from other studies, as it is a study of $\mathrm{C}_{2} \mathrm{H}_{6}$ (rather than a direct $\mathrm{CH}_{4}$ measurement). Whereas there is uncertainty in the $\mathrm{CH}_{4} / \mathrm{C}_{2} \mathrm{H}_{6}$ ratios used to model $\mathrm{CH}_{4}$ emissions, the use of $\mathrm{C}_{2} \mathrm{H}_{6}$ has some advantages in that it rules out biogenic sources of $\mathrm{CH}_{4}$.

\section{Pétron et al.}

Pétron et al. (3) create three cases that we include in the first text chart as a median case with high-low ranges (as recommended by study author G. Pétron through personal communication). See below for discussion of the methods used in Pétron et al. This study estimates emissions from the NG and petroleum industry in the Denver-Julesberg basin. They report emissions of 71.6 to $251.9 \mathrm{Gg} \mathrm{CH}_{4} /$ year, as gathered from table 4 in the original source. Using suggested cases from original study author (Pétron) we choose low, med, and high case estimates of $0.071,0.129$, and $0.259 \mathrm{Tg} \mathrm{CH}_{4} /$ year, respectively. Pétron et al. compare their emissions estimate to emissions estimated in the Western Regional Air Partnership (WRAP) air pollutant inventory for the time and region of interest. The comparable estimate is $64.3(46-86) \mathrm{Gg} \mathrm{CH}_{4}$. This leads to a central estimate for the ratio of measured/estimated of $2.0 \mathrm{~g} / \mathrm{g}$. 
Levi (25) creates a number of cases in his assessment that we include in the first text chart. See below for discussion of the methods used in Levi. In general, Levi reinterprets the results from the Pétron et al. study to estimate emissions for the Denver Julesberg basin. He reports a range of emissions estimates in table 2 in the original source, which range from 46.4 to $58.8 \mathrm{Gg} \mathrm{CH}_{4} /$ year. For our comparison, we construct ranges as follows. Our central estimate is given by the average of the four "expected" values [min and max ranges for both Boulder Atmospheric Observatory (BAO) and mobile lab]. Our low estimate is given by lowest "expected" value less the lower bound "conservative error" quantity (mobile lab minimum). Our high estimate is highest expected value plus the "conservative error" upper bound (BAO maximum). Levi compares their[BPO2] emissions estimate to the same WRAP emissions inventory for the time and region of interest. This leads to a central estimate for the ratio of measured/estimated to be 0.8 ($0.3,+0.9) \mathrm{g} / \mathrm{g}$.

\section{Wunch et al.}

Wunch et al. (12) create two cases that we include in the first text chart. See below for discussion of the methods used in Wunch et al. Both cases estimate emissions for the South Coast Air Basin (SoCAB). The two cases differ in the gas species that they use to scale observations of $\mathrm{CH}_{4}$ concentrations to obtain fluxes of $\mathrm{CH}_{4}$. In one case, they use the ratio of $\mathrm{CO}_{2}$ to $\mathrm{CH}_{4}$ in well-mixed air along with an average of EDGAR and CARB $\mathrm{CO}_{2}$ emissions estimates to provide an estimate of $\mathrm{CH}_{4}$ fluxes. In the other case, they use the CARB CO inventory to estimate $\mathrm{CH}_{4}$ fluxes. They report emissions of $0.6( \pm 1) \mathrm{Tg}$ $\mathrm{CH}_{4}$ /year and $0.4( \pm 1) \mathrm{Tg} \mathrm{CH}_{4} /$ year in these two cases, as presented in table 2 in the original source. Wunch et al. compare their emissions estimate to an urban-regionfocused, population-scaled modification of the $\mathrm{CARB} \mathrm{CH}_{4}$ inventory for the time and region of interest. The comparable estimate is $0.26 \mathrm{Tg} \mathrm{CH}_{4} /$ year. This leads to a central estimate for the ratio of measured/estimated to be $2.3 \mathrm{~g} / \mathrm{g}$ and $1.5 \mathrm{~g} / \mathrm{g}$ in the $\mathrm{CO}_{2}$-scaled and $\mathrm{CO}$-scaled cases, respectively.

\section{Hsu et al.}

Hsu et al. (10) create one case that we include in the first text chart. See below for discussion of the methods used in Hsu et al. This case estimates emissions for Los Angeles County within SoCAB. They report emissions of $4.2( \pm 0.12) \mathrm{Mt} \mathrm{CO}_{2}$ eq./year, as gathered from table 3 in the original source. We convert this estimate to $0.2( \pm 0.01) \mathrm{Tg}$ $\mathrm{CH}_{4} /$ year using the same GWP used by Hsu et al. (21 $\mathrm{g} \mathrm{CO}_{2}$ eq./g CH $\mathrm{CH}_{4}$. Hsu et al. compare their emissions estimate to the $\mathrm{CARB} \mathrm{CH}_{4}$ inventory for the time and region of interest. The comparable estimate is $3 \mathrm{Mt} \mathrm{CO}_{2} \mathrm{eq} /$ year. This leads to a central estimate for the ratio of measured/estimated of $1.4 \mathrm{~g} / \mathrm{g}$. 


\section{Wennberg et al.}

Wennberg et al. (7) create one case that we include in the first text chart. See below for discussion of the methods used in Wennberg et al. This cases estimates emissions in the SoCAB for all sources of $\mathrm{CH}_{4}$. They report emissions of $0.44 \mathrm{Tg} \mathrm{CH}_{4} /$ year, as gathered from table 3 in the original source. Wennberg et al. compare their emissions estimate to a modified version of the CALGEM spatial inventory for the time and region of interest. The comparable estimate is $0.212 \mathrm{Tg} \mathrm{CH}_{4} /$ year, respectively. This leads to a central estimate for the ratio of measured/estimated of $2.1 \mathrm{~g} / \mathrm{g}$.

Wennberg et al. also compute a "maximum possible" emissions rate from the NG industry, which is not significantly less than their total emissions rate $\left(0.39 \mathrm{Tg} \mathrm{CH}_{4} /\right.$ year $)$. Because this is meant to represent an upper-bound constraint on possible emissions from $\mathrm{NG}$, rather than a best estimate of the magnitude, we do not include this result in our comparison.

\section{Peischl et al.}

Peischl et al. (2) create two cases that we include in the first text chart. See below for discussion of the methods used in Peischl et al. Their cases estimate emissions of $\mathrm{CH}_{4}$ into the SoCAB from all $\mathrm{CH}_{4}$ sources, as well as from $\mathrm{NG}$ and petroleum sources. In an advance from previous work, they create estimates for subsources of gas within the NG and petroleum sectors, including pipeline-quality dry gas, and unprocessed raw gas. They report emissions of $411( \pm 37) \mathrm{Gg} \mathrm{CH}_{4} /$ year for all sources and $223( \pm 61) \mathrm{Gg} \mathrm{CH}_{4} /$ year for NG emissions, respectively. Because Peischl et al. estimate a variety of subsources, we include the following sources in our estimate of NG emissions: "pipeline quality dry NG/Local seeps" and "Local NG." These results are gathered from table 4 in the original source. Peischl et al. compare their emissions estimate to the CARB 2009 GHG inventory for the region of interest. The comparable estimates from the CARB inventory are $301 \mathrm{Gg} \mathrm{CH}_{4} /$ year and $64.6 \mathrm{Gg} \mathrm{CH}_{4} /$ year, respectively. This leads to a central estimate for the ratio of measured/estimated of $1.4 \mathrm{~g} / \mathrm{g}$ for the case of all emissions sources and 3.5 $\mathrm{g} / \mathrm{g}$ for the NG sources. We refer to this case as a "NG + petroleum" case, as the nature of NG production in SoCAB is almost entirely associated with oil production, which EPA would classify then as a "petroleum" sector source.

\section{Karion et al.}

Karion et al. (1) create one case that we include in the first text chart. See below for discussion of the methods used in Karion et al. The case of interest estimates emissions for NG operations in the Uintah basin, UT. They report $\mathrm{CH}_{4}$ emissions of 54,600 $( \pm 15500) \mathrm{kg} / \mathrm{h}$, as gathered from paragraph 15 in the original source, equal to 0.48 $( \pm 0.14) \mathrm{Tg} \mathrm{CH}_{4} /$ year. Karion et al. compare their emissions estimate to the WRAP 
inventory for the time and region of interest. The comparable estimate is $30,333 \mathrm{~kg} / \mathrm{hour}$. This leads to a central estimate for the ratio of measured/estimated to be $1.80 \mathrm{~g} / \mathrm{g}$.

\section{Chambers}

Chambers (14) creates eight cases that we include in the first text chart. See below for discussion of the methods used in Chambers. Chambers estimates emissions for tanks, flares, fugitive emissions, and glycol dehydrators. He reports emissions of 19.3 to $1165 \mathrm{t}$ $\mathrm{CH}_{4}$ /year as gathered from tables 18 and 21 in the original source. Chambers compares his emissions estimate to Canadian Association of Petroleum Producers (CAPP) detailed EF estimates for the technologies of interest. The comparable estimates using CAPP EF methods range from 0.3 to $240 \mathrm{tCH}_{4} /$ year. This leads to a central estimate for the ratio of measured/estimated which range from $2.1 \mathrm{~g} / \mathrm{g}$ to $128.6 \mathrm{~g} / \mathrm{g}$.

The full details for Chamber's eight estimates can be found in Data File S1.

\section{Harrison et al.}

Harrison et al. (18) create fifteen cases that we include in the first text chart. These cases include estimates for the following sources. We also report the total number of components screened.

- Valves: 1634 components screened

- Flanges: 1244 components screened

- Centrifugal compressor - Average BD vent for run: 3 components screened

- Centrifugal compressor - Average BD vent for idle + run: 11 components screened

- Centrifugal compressor - Wet seal (run): 9 components screened

- Reciprocating transmission compressor - Average BD vent for idle + pressurized: 10 components screened

- Reciprocating transmission compressor - Average BD vent for run: 6 components screened

- Reciprocating transmission compressor - Average BD vent for idle + depressurized: 15 components screened

- Reciprocating transmission compressor - Average rod packing for idle + pressurized: 5 components screened

- Reciprocating transmission compressor - Average rod packing for run: 2 components screened

- Reciprocating boosting compressors - Average BD vent for run: 16 components screened

- Reciprocating boosting compressors - Average BD vent for idle + depressurized: 8 components screened

- Reciprocating boosting compressors - Average PRV vent for run: 12 components screened 
- Reciprocating boosting compressors - Average PRV vent for idle + depressurized: 6 components screened

- Reciprocating boosting compressors - Average rod packing - Run: 15 components screened

See below for discussion of the methods used in Harrison et al. They report emissions ranging from 0 to $29693 \mathrm{MSCF} / \mathrm{year}$, as gathered from tables 3-2, 3-3, 3-4, and 3-5 in the original source. These emissions factors are for unspecified gas composition, but it appears that the Hi-Flow sampler is used to estimate emissions of $\mathrm{CH}_{4}$ on a volumetric basis (e.g. discussion of $\mathrm{CH}_{4}$ concentration calibration in report p. 35 and units reported in headings in table 3.3). However, this is not entirely clear, as some Harrison et al. results tables do not specify whether units are $\mathrm{MSCF} /$ year of $\mathrm{CH}_{4}$ or are $\mathrm{MSCF} /$ year of total hydrocarbons. Harrison et al. compare their emissions estimate to relevant EPA/GRI emissions factors for the technology of interest. The comparable volumetric EPA EFs range from 0 to $9352 \mathrm{MSCF} /$ year.

The comparable EPA emissions factors are presented by Harrison et al. in identical volumetric units (MSCF/year). As the Hi-Flow sampler results appear to be reporting the volume of $\mathrm{CH}_{4}$ leakage (e.g., MSCF $\mathrm{CH}_{4} /$ year rather than MSCF total hydrocarbons/year), Harrison et al. should be comparing their results to MSCF/year of $\mathrm{CH}_{4}$ emissions, not MSCF of total hydrocarbon emissions. It appears that their comparable EPA EFs are also reported on a $\mathrm{CH}_{4}$ volumetric basis (e.g., Harrison et al. cite EPA/GRI 1996, Vol. 8, table 4-15, which adjusts total leakage volume to account for $93.4 \mathrm{~mol}_{\mathrm{O}} \mathrm{CH}_{4}$ in transmission quality gas). In this case, comparing standard volumes of $\mathrm{CH}_{4}$ emissions allow for either volume/volume or mass/mass $(\mathrm{g} / \mathrm{g})$ ratios to be computed.

\section{Clearstone}

Clearstone Engineering Ltd. (15) create 12 cases that we include in the first text chart. See below for discussion of the methods used in the Clearstone report. The Clearstone report estimates emissions for the following devices:

- Connector: 82146 components screened

- Block valves: 15136 components screened

- Control valves: 1240 components screened

- Pressure relief valves: 385 components screened

- Pressure regulators: 169 components screened

- Orifice meters: 167 components screened

- Other flow meters: 7 components screened

- Crank case vents: 36 components screened

- Open ended lines: 1610 components screened

- Pump seals: 83 components screened

- Compressor seals: 206 components screened

- Blowdowns: 6 components screened 
The Clearstone report estimate emissions factors ranging from 0.002 to $0.883 \mathrm{~kg}$ total hydrocarbons/h/source, as gathered from table 5 (p. 28) in the original source. Clearstone compares their emissions estimate to EPA/GRI (1996[BPO3]) emissions factors, as well as EPA (1995[BPO4]) emissions factors. The Clearstone report notes that EPA EFs are presented in $\mathrm{CH}_{4}$ basis only, and so are not exactly comparable to the reported total hydrocarbon EFs (e.g., an unknown factor of 0.8-0.95 likely needed to convert between these two EFs). We assume comparison to the EPA/GRI (1996[BPO5]) EFs is more appropriate, as these form the major basis of the current EPA GHGI. The comparable estimates range from 0 to $5.53 \mathrm{~kg} \mathrm{CH}_{4} / \mathrm{h} /$ source. This leads to a central estimate for the ratio of measured/estimated to range from 0.2 to $30.1 \mathrm{~g} / \mathrm{g}$. Because Clearstone does not report gas composition and measures total hydrocarbon emissions, these ratios are likely high by an (uncertain) factor of $\sim 1 / 0.9$. In deference to our goal of using directly reported data in the main part of the first chart, we do not correct this discrepancy.

\section{NGML}

National Gas Machinery Laboratory (NGML), Clearstone Engineering Ltd., and Innovative Environmental Solutions Inc. (21) create nine cases that we include in the first text chart. See below for discussion of the methods used in NGML et al. This report estimates emissions for:

- Connectors: 64369 components screened

- Block valves: 7692 components screened

- Control valves: 495 components screened

- Pressure relief valves: 124 components screened

- Pressure regulators: 320 components screened

- Orifice meters: 57 components screened

- Crank case vents: 27 components screened

- Open ended lines: 1055 components screened

- Compressor seals: 299 components screened

NGML et al. report emissions of 0 to $0.52 \mathrm{~kg}$ total hydrocarbons $/ \mathrm{h} / \mathrm{source}$, as gathered from table 4 (p. 31) in the original source. NGML et al. compare their emissions estimate to the EPA/GRI (1996) EFs for the technology of interest. The NGML report notes that EPA EFs are presented in $\mathrm{CH}_{4}$ basis only, and so are not exactly comparable to reported total hydrocarbon EFs (e.g., an unknown factor of 0.8-0.95 likely needed to convert between these two EFs). The comparable EFs range from 0 to $1.17 \mathrm{~kg} \mathrm{CH}_{4} / \mathrm{source} / \mathrm{h}$. This leads to a range of central estimates for the ratio of measured/estimated to be of 0.2 to $10.8 \mathrm{~g} / \mathrm{g}$. Because NGML et al. do not report gas composition and instead measure total hydrocarbon emissions, these ratios are likely high by an (uncertain) factor of approx. 1/0.9. In deference to our goal of using directly reported data in the main part of the first text chart, we do not correct this discrepancy. 
The Gas Technology Institute (GTI) study (16) create three estimates for emissions from distribution equipment that we include in the first text chart. See below for discussion of the methods used in GTI. The GTI study estimates emissions from the following sources:

- Commercial meters: 836 components screened

- Industrial meters: 46 components screened

- Residential meters: 2400 components screened

- District regulator stations: 77 components screened

- Pressure limiting stations: 11 components screened

- Custody transfer stations: 37 components screened

- Vehicle compressor stations: 10 components screened

Because comparisons were not broadly made in the GTI study to EPA EFs, figure 1 only includes residential meters, commercial meters, and industrial meters. They report emissions ranging between 2 and $8602 \mathrm{lbs} \mathrm{CH}_{4} / \mathrm{h}$, as gathered from table 3 in the original source. GTI compares their emissions estimate to EPA/GRI Tier 3 EFs for the devices of interest. The comparable estimates are 2.0 to $5.8 \mathrm{lbs} \mathrm{CH}_{4} / \mathrm{h}$. This leads to a range of central estimate for the ratio of measured/estimated of 0.4 to $4254 \mathrm{~g} / \mathrm{g}$.

\section{Allen et al.}

Allen et al. (26) create four estimates that we include in the first text chart. See below for discussion of the methods used in Allen et al. They estimate emissions, as useful for our purposes, for the following sources:

- hydraulic fracturing flowback emissions,

- chemical pumps,

- pneumatic controllers, and

- general equipment leaks.

These estimates were made by sampling 27 well completions, 9 gas well unloading events, 4 well workovers, and 489 wells in normal operation (see table 1 in original source). Allen et al. report emissions ranging from 0.6 to $2.2 \mathrm{Mg} \mathrm{CH}_{4} /$ unit per year for these sources. These results are gathered from table 2 in the main text of the original source, as central estimates plus uncertainty ranges in $\mathrm{Gg} \mathrm{CH}_{4} / \mathrm{year}$. The results presented in Allen at al. main text are large in magnitude because they have been scaled to a national level using activity factors from the EPA inventory (generally region specific activity factors). Using the activity data from table S5-2 in the original source Supporting Information, we can compute ranges for low, central, and high emissions per unit. These per unit emissions can then be compared to the appropriate EPA inventory EF, as given in table S5-3 in the original source supporting information. Allen et al. compare their emissions estimate to the EPA inventory EFs (net of controls and regulatory reductions) for the technology of interest. The comparable estimates range from 0.3 to $8 \mathrm{Mg}$ $\mathrm{CH}_{4} /$ device/year. This leads to central estimates for the ratio of measured/estimated emissions that range from 0.03 to $2 \mathrm{~g} / \mathrm{g}$. 


\subsubsection{The first text chart (inset): Adjustment of atmospheric estimates to scaled EPA GHGI}

In order to make estimates in the main part of the first text chart more comparable, we normalize all ratios for studies at the regional atmospheric scale or larger. We normalize all these studies to the most recent EPA greenhouse gas inventory (GHGI). This inventory covers the years up to 2011, but was published in 2013, so we henceforth refer to it as the 2011/2013 GHGI (17). If a study already uses the EPA GHGI emissions factors for its comparison to inventory or EF, we do not make any adjustment to the ratio as reported in the study.

For each study, we normalize the GHGI estimate to the appropriate study spatial and sectoral boundary. In essence, we multiply the estimated national emissions from the GHGI by a scaling factor representing the fraction of activity in the region and sectors of interest (e.g., $11 \%$ of population, or $16 \%$ of $\mathrm{NG}$ end use consumption).

Some top-down studies use measurements sensitive to Canadian emissions [e.g., $(5,6)]$. These samples represent a small fraction of the observations considered in these respective analyses. These studies calculate a scaling factor, that when applied to the spatially-resolved EDGAR inventory, best matches observations. This scaling factor is applied uniformly to EDGAR (including Canada), but is most robust where observations are densest over the United States. The observationally derived scaling factor (e.g., Kort et al. ratio of $1.08 \mathrm{~g} / \mathrm{g}$ relative to EDGAR v3.2), can then be applied to EDGAR U.S. emissions to estimate total U.S. emissions (e.g., $32.4 \mathrm{TgC} /$ year in Kort et al.). These overall U.S. emissions can then be compared to EPA inventory. Some of the largest-scale atmospheric studies will show some influence of Canadian emissions, but any distortion due to this effect is likely to be small, owing to relative paucity of Canadian samples used in these studies and due to similarities in Canadian and U.S. drilling and production practice.

The following steps were taken for each study to generate a comparably scaled EPA GHGI emissions estimate:

\subsubsection{Step 1: Determine study year}

The study year is defined as the year in which measurements were taken or a key year of study measurements if multiple years of data are included.

\subsubsection{Step 2: Collect emissions estimate for study year}

EPA 2011/2013 GHGI estimates for anthropogenic emissions of $\mathrm{CH}_{4}$ from all sources are collected for the study year.

\subsubsection{Step 3: Determine appropriate sectoral and regional scaling}


The appropriate scaling boundary for each study is then determined. In some cases, this scaling factor represents a regional boundary (e.g., South Coast air basin), in which case the scaling might be performed using the fraction of population present in the study's spatial boundary to the total U.S. population. In other cases, our scaling of the EPA GHGI is developed by matching to the same sector(s) that the study intended to measure $\mathrm{CH}_{4}$ emissions from (e.g., estimate is of oil and gas emissions). If an author makes a quantitative attribution of $\mathrm{CH}_{4}$ emissions to a particular sector or sub-sector (e.g., the author estimates leakage of pipeline quality NG) we utilize that judgment to create an appropriately scaled inventory for comparison.

\subsubsection{Step 4: Generate scaling factors for included sources.}

Scaling factors for each study were generated as described below.

\subsection{Natural gas emissions by industry sector}

Natural gas production sector emissions are scaled by the fraction of total United States non-associated gross gas production in the study area of interest. Oil-associated gas production is removed from both the numerator (production in the basin) and denominator (total U.S. production) because oil associated gas production emissions are included within the EPA GHGI petroleum inventory, not within the EPA GHGI NG inventory (31). EIA data sources are used in general to scale production emissions. For regional (e.g., sub-state scale) studies, regional production statistics are used from state reporting agencies (See Data File S1 for detailed listing of sources).

Natural gas processing sector emissions are scaled by the fraction of U.S. gas processed in the study region of interest. For regions where gas processing volumes are not available, volumes of gas processed are estimated. First, total gas production (associated and non-associated) volumes are computed as the feedstock for gas processing. We then assume that the fraction of gas processed is equal to the U.S. average processing fraction for 2011. This fraction is computed on either a net or gross output basis, depending on nature of reported gas production statistics. Using either reported or estimated processed gas, the share of U.S. gas processing that occurred in the study region is computed. These data are generally collected from EIA (see Data File S1 for detailed listing of sources).

Transmission sector emissions would ideally be estimated using the fraction of national gas transmission in a region. Because the volume of gas transmitted through a region is generally not available, an estimate of transport intensity is generated based on production and consumption shares in the region of interest. The weighting factor for gas transmitted is estimated as the simple average of the regional share of dry gas produced and the regional share of gas consumed in the region. EIA data are used where applicable (see Data File S1 for details).

Distribution sector emissions are scaled by the fraction of U.S. gas consumption in the region. Fractional consumption is computed on the basis of gas volumes delivered to 
consumers. EIA data are used here, except in cases where consumption is not reported on a sub-state basis, in which case regional consumption data or population are used to scale the estimates of consumption.

\subsection{Petroleum emissions}

Petroleum emissions are scaled by the fraction of U.S. petroleum production for the study year that occurred in the study region. EIA data are generally used. Sub-state data from state regulators (for regional air studies) are used in some cases. See Data File S1 for details.

\subsection{Coal mining emissions}

Coal mining emissions are scaled by the fraction of coal production for the study year occurring within the study region. EIA data are used where applicable, as are sub-state data where needed (for regional atmospheric studies). See Data File S1 for details.

\subsection{Livestock emissions}

Manure management and enteric fermentation emissions are scaled by the fraction of U.S. cattle contained in the study region. Data are generally provided by USDA regional livestock statistics (see Data File S1 for details). Cattle provide a first approximation of enteric and manure emissions sources, because cattle represent $\sim 95 \%$ of emissions from enteric fermentation [table A-195 in (31)], 55\% of emissions from manure management [table A-205 in (31)], and 85\% of total livestock emissions.

\subsection{Landfill emissions}

Landfill emissions are scaled using the fraction of U.S. population in the region. In California cases, it is known experimentally that California landfill emissions rates are lower than national averages due to stronger $\mathrm{CH}_{4}$ capture regulations (2). For this reason, California average landfill emissions factors are applied to California studies (a scaling factor of $\sim 0.5$ relative to national emissions rates).

\subsection{Other sources}

All other sources are scaled by the fraction of U.S. population living in the region.

\subsubsection{Step 5: Scale EPA GHGI emissions}


Using the region- and sector-specific study scaling factors calculated as above, we scale emissions from the GHGI for the study year to the study region. Note that for each study, the result from the 2011/2013 EPA GHGI (17) is used for the year in which measurements were made, not for the most current year of the inventory. Because the 2011/2013 EPA GHGI contains estimates for the years 1990 to 2011, all studies except one contain data from the GHGI for the year in which measurements were made (1). For the case of Karion et al., which contains measurements from 2012, EPA GHGI estimates from 2011 were used. Central estimates from the EPA GHGI were used due to lack of ability to apply EPA uncertainty ranges to sub-national scales.

Details of scaling for each study are described below.

\section{Miller et al. 2013}

Miller et al. (6) create multiple estimates for $\mathrm{CH}_{4}$ emissions. National scale emissions are estimated as $33.4 \pm 1.5 \mathrm{Tg} \mathrm{C}$ as $\mathrm{CH}_{4}$ per year. Regional emissions for the South-Central United States (TX, OK, KS) are estimated as $8.1 \pm 0.96 \mathrm{Tg} \mathrm{C}$ as $\mathrm{CH}_{4} / \mathrm{year}$. Also, using the fitted sources for the South-Central U.S. region, they estimate possible emissions of C as $\mathrm{CH}_{4}$ of $3.7 \pm 2 \mathrm{Tg} /$ year from the oil and gas industry.

The national-scale estimate is converted to $\mathrm{Tg}_{\mathrm{CH}}$ and compared to the national-scale estimate for 2008 from the EPA 2011/2013 GHGI. The regional estimate for the SouthCentral United States is compared to a scaled EPA 2011/2013 GHG for the study region, using state-level data reported by EIA. Estimated excess emissions from the oil and gas industry are compared to regional inventoried emissions from the NG and petroleum sectors.

Kort et al. 2008

The estimate of total national emissions from Kort et al. (5) for 2003 is $32.4 \pm 4.5 \mathrm{Tg} \mathrm{C}$ as $\mathrm{CH}_{4} /$ year from all sources. Kort et al. compare this estimate to EDGAR v3.2 estimates for U.S. emissions $\left(30 \pm 2.87 \mathrm{Tg} \mathrm{C}\right.$ as $\left.\mathrm{CH}_{4}\right)$.

We convert the Kort et al. estimate for 2003 emissions to $\mathrm{Tg} \mathrm{CH}_{4}$ and compare this estimate to the EPA 2011/2013 GHGI estimate for the year 2003. No scaling is applied, as Kort produces a national estimate.

Xiao et al. 2008

Xiao et al. (8) use $\mathrm{C}_{2} \mathrm{H}_{6}$ measurements and 3 cases of possible $\mathrm{CH}_{4} / \mathrm{C}_{2} \mathrm{H}_{6}$ ratios from fossil fuel sources to arrive at three estimates for possible $\mathrm{CH}_{4}$ emissions from energy industries (NG, petroleum, coal). Estimated $\mathrm{CH}_{4}$ emissions from these industries are 13.3, 
16.0, and 24.0 $\mathrm{Tg} \mathrm{CH}_{4}$. Xiao et al. compare these estimates to estimates for $2004 \mathrm{CH}_{4}$ emissions from these industries from both the 2007 and 2008 EPA GHGI.

We compare the estimated $\mathrm{C}_{2} \mathrm{H}_{6}$ emissions from Xiao et al. to estimates for $\mathrm{C}_{2} \mathrm{H}_{6}$ generated from the $2011 / 2013 \mathrm{GHGI} \mathrm{CH}_{4}$ estimate from the energy industries. We scale $\mathrm{CH}_{4}$ emissions from the energy industries (NG, petroleum, and coal) by the same $\mathrm{CH}_{4} /$ $\mathrm{C}_{2} \mathrm{H}_{6}$ ratios used in Xiao to arrive at implied $\mathrm{C}_{2} \mathrm{H}_{6}$ emissions.

Wang et al. 2004

Xiao notes that Wang et al. (13) found emissions of $20 \mathrm{Tg} \mathrm{CH}_{4} /$ year from energy production in the United States for 1998. The source of this estimate was not found in the Wang et al. paper, and is cited as a personal communication in Xiao. It appears to be a regional result extracted from the global assessment of Wang (e.g., Wang's paper focused on global results, but regional results were also generated). Xiao compares this estimate from Wang to an estimate of $10 \mathrm{Tg} \mathrm{CH}_{4}$ /year from the energy industries.

We compare the Wang estimate of $20 \mathrm{Tg} \mathrm{CH}_{4}$ year to the EPA 2011/2013 GHGI estimate for 1998 for the primary energy industries (NG, petroleum and coal).

\section{Katzenstein et al. 2003}

Katzenstein et al. (9) estimate emissions of 4-6 $\mathrm{Tg} \mathrm{CH}_{4}$ per year in the South Central United States (TX, OK, KS). Katzenstein et al. compare this emissions rate to a rate of 4 $8 \mathrm{Tg} \mathrm{CH}_{4}$ per year from oil and gas industries, using a 1997 EPA source as the basis for comparison.

We compare the Katzenstein et al. emissions estimate for the region to a scaled version of petroleum and NG emissions from the region. The EPA 2011/2013 GHGI estimate for 2001 emissions from NG and petroleum sources is scaled to the region using the fractional production of oil and gas in the region in 2001.

We note that attribution in Katzenstein is made to the hydrocarbon industries (NG and petroleum) on the basis of evidence from higher alkane prevalence. They do not appear to do any rigorous attribution of emissions to the possible sources in the region.

Pétron et al. 2012

Pétron et al. (3) estimate emissions from the Denver-Julesberg (DJ) basin of $129.6 \mathrm{Gg}$ $\mathrm{CH}_{4}$ (71.6 - 251.9). They compare this estimate to WRAP inventory estimates of $64.3 \mathrm{Gg}$ $\mathrm{CH}_{4}(46-86)$. Because the estimate of Pétron et al. is created by scaling higher hydrocarbons $\left(\mathrm{C}_{3} \mathrm{H}_{8}\right)$ that have no significant biological sources, it is fundamentally an estimate of $\mathrm{NG}$ and petroleum emissions. 
We create a basin-level scaled estimate of GHG emissions from oil and gas operations by scaling the EPA 2011/2013 GHGI emissions from oil and gas operations to local production. Because isolating wind direction is used to exclude emissions from the nearby Denver metropolitan area, we exclude distribution and transmission emissions from this large population center. We do include consumption within Weld County itself, as scaled by fraction of U.S. population within the study region.

Production in the DJ basin in 2008 equaled $17.6 \times 10^{6} \mathrm{bbl}$ of petroleum and 204.4 BCF of NG. In figure 4 of a reply to Levi (32), Pétron et al. note that $40 \%$ of the NG production in the DJ basin comes from wells classified by GOR as "dry" gas or "leaning dry". We assume that this production would be classified as gas wells in the EPA methodology, while other gas would be classified as production of oil-associated gas.

Levi 2012

Levi (25) re-analyzes the Pétron data, using $\mathrm{C}_{4} \mathrm{H}_{10}$ inventory fluxes and the $\mathrm{C}_{4} \mathrm{H}_{10}$ to $\mathrm{CH}_{4}$ ratios observed in the atmosphere to scale $\mathrm{CH}_{4}$ concentrations to flux. He estimates a central flux of $51.8 \mathrm{Gg} \mathrm{CH}_{4} /$ year (42.5 -78.9). Levi then compares these to the WRAP inventory for the region.

We compare the Levi estimates to the scaled EPA GHGI for the year 2008 for the DJ basin, constructed identically to that for Pétron et al. above.

Wunch et al. 2009

Wunch et al. (12) estimate emissions of $0.6 \pm 1 \mathrm{Tg} \mathrm{CH}_{4} /$ year for the South Coast Air Basin (SoCAB) for the 2007-2008 time frame (August 2007 to June 2008). They compare this estimate to a scaled version of the CARB inventory for urban $\mathrm{CH}_{4}$ fluxes.

We construct a regionally-scaled EPA 2011/2013 GHGI for the years 2007-2008, following the methodology noted above with county-level SoCAB data.

Hsu et al. 2010

Hsu et al. (10) estimate $\mathrm{CH}_{4}$ emissions in the portion of Los Angeles county contained within the SoCAB. They estimate emissions of $0.2 \mathrm{Tg} \mathrm{CH}_{4}\left( \pm 0.01 \mathrm{Tg} \mathrm{CH}_{4}\right)$. They compare these estimates to a scaled version of the CARB state GHG inventory for the region.

We construct a scaled estimate of the EPA 2011/2013 GHGI for the region in a similar fashion to that of the Wunch et al. study above. One note of interest: some emissions sources are scaled by the fraction of U.S. population in Los Angles county within the 
study region. To approximate this study region, we take the population of Los Angeles county and subtract the populations of Lancaster and Palmdale, two key cities in the nonSoCAB portion of Los Angeles county.

Wennberg et al. 2012

Wennberg et al. (7) estimate emissions of all sources of $0.44(0.4-0.48) \mathrm{Tg} \mathrm{CH}_{4} /$ year. They estimate the "maximum contribution" from the gas system of $0.38(0.23-0.53) \mathrm{Tg}$ $\mathrm{CH}_{4} /$ year.

We compare the results for all sources to a regionally-scaled version of the 2011/2013 EPA GHGI for the year 2008.

Peischl et al. 2013

Peischl et al. (2) estimate total emissions in the SoCAB of $0.411(0.374-0.448) \mathrm{Tg}$ $\mathrm{CH}_{4}$ /year. They further estimate sources associated with oil and gas activities of 0.224 $(0.163-0.285) \mathrm{Tg} \mathrm{CH}_{4} /$ year.

We compare these results to regionally-scaled versions of the 2011/2013 EPA GHGI for the year 2010. We construct two scaling cases. First we construct an "all sources" case that includes all plausible sources from the GHGI in the SoCAB. We also construct a NG and petroleum sources case, which scales NG and petroleum sources from the 2011/2013 EPA GHGI to the region (production, processing, transmission, and distribution).

Karion et al. 2013

Karion et al. (1) estimate oil and gas operations emissions of $54.6(39.1-70.1)$ t $\mathrm{CH}_{4} / \mathrm{h}$, or $0.478(0.343-0.614) \mathrm{Tg} \mathrm{CH}_{4} /$ year in Uintah county. Estimates in Karion et al. were made based on measurements taken in 2012.

We compare this to a scaled version of results from 2011 for the EPA 2011/2013 GHGI that includes NG, petroleum, and other sources. Cattle-associated sources (enteric fermentation and manure management) are removed from our comparable GHGI estimate because Karion et al. remove cattle emissions from their estimate. For completeness, we do include population scaled emissions sources but these are trivial in the region of interest (no significant population centers in the Uintah basin).

\subsubsection{Step 6: Compute normalized ratios}


Using the scaled EPA GHGI estimate, we compute the ratio between the author estimates (central, low, high) and the scaled EPA GHGI.

These calculations are recorded in the Data File S1 in the "Calc - Figure 1 - Inset" worksheet.

\subsubsection{The second text chart: Exploration of possible sources of excess $\mathrm{CH}_{4}$}

The second text chart illustrates possible sources of excess $\mathrm{CH}_{4}$ for the $\mathrm{NG}$ sector relative to the national EPA GHGI of 2011. The second chart also includes sources that could confound estimated NG emissions, such as petroleum system emissions or natural seeps. Note: The second chart is intended as an order of magnitude "thought experiment" to explore potential magnitude of possible source contributions to excess $\mathrm{CH}_{4}$ emissions, given currently available evidence. The resulting uncertainty ranges on source contributions are large, as might be expected from the current state of knowledge of leakage sources.

These calculations are recorded in Data File S1 in the "Calc - Figure 2" worksheet.

\subsubsection{Baseline excess $\mathrm{CH}_{4}$}

The first text chart (inset) suggests that, based on current evidence, the ratio of measured and inventoried $\mathrm{CH}_{4}$ emissions is approximately $\sim 1.5$ at multi-state and larger scales (5, 6 , 8). We utilize this excess ratio to scale emissions from the EPA GHGI by a factor of $1.5( \pm 0.25)$ so as to develop an estimate of the range of possible national excess $\mathrm{CH}_{4}$. This results in baseline excess $\mathrm{CH}_{4}$ emissions rate of $14( \pm 7) \mathrm{Tg} \mathrm{CH}_{4}$. This range is plotted as the blue bar in the second chart in the main text.

Importantly, this excess includes any sources of $\mathrm{CH}_{4}$ that are emitted in excess of EPA GHGI estimates. For example, there are indications that $\mathrm{CH}_{4}$ emissions from livestock are poorly understood (33). A recent atmospheric study suggested that livestock emissions could be underestimated by $5.7 \mathrm{Tg} \mathrm{C}$ per year (6). It should therefore not be expected that $\mathrm{NG}$ sources would make up all of estimated excess $\mathrm{CH}_{4}$ in the second text chart.

\subsubsection{2 "Upstream" emissions: Natural gas production and processing leakage in excess of EPA GHGI estimates}

Leakage from upstream operations (production and processing) could be in excess of rates estimated in EPA inventories. Several recent studies estimate high emissions from production and processing operations $(1,3,45)$.

The Pétron et al. study 3) found a central estimate of 4\% leakage from the DenverJulesberg basin. The Karion et al. study $(1,45)$ found a central estimate of $8.9 \%$ leakage 
from the Uintah basin. We consider the Karion et al. study results as the emissions rate for "high emitting" NG production and processing operations. We assume for purposes of comparison to the EPA GHGI that both of these studies measure all emissions from production, gathering, tanks, and gas processing, in addition to $25 \%$ of emissions from transmission (due to initial compression work to bring gas to the transmission pressure).

No data are available on the fraction of gas production that occurs at "high emitting" gas production and processing operations. In 2012, the Uintah basin produced approximately $1.4 \%$ (320 BCF) of gross U.S. gas production (see Data File S1 for sources). The second text chart plots three illustrative prevalence cases:

- Low: $1 \%$ of gas production and processing occurs from "high emitting" gas fields

- Medium: $10 \%$ of gas production and processing occurs from "high emitting" gas fields

- High: $25 \%$ of gas production and processing occurs from "high emitting" gas fields

These three cases result in excess emissions above EPA GHGI emissions of 0.54 to 9.43

$\mathrm{Tg} \mathrm{CH} /$ year. EPA GHGI emissions in this sector were equal to $\sim 1.5 \mathrm{Tg} \mathrm{CH}_{4}$ in the study year (see Data File S1). These Low, Medium and High cases for excess upstream emissions are plotted as points $a, b, c$ in the "NG production and processing" bar in the second chart in the main text.

Given the high leakage rates estimated in these studies $(1,3)$, it is unlikely that a significant fraction of North American gas fields have leakage rates at this "high emitter" rate (as total excess $\mathrm{CH}_{4}$ in the second text chart would be more than satisfied).

\subsubsection{3 "Downstream" sources: Natural gas distribution and end-use leakage in excess of EPA estimates}

Leakage from downstream sources (distribution and end use of gas) also could be in excess of amounts estimated in EPA inventories. The Wennberg et al. study (7) found a central estimate of $3.5 \%$ leakage from the distribution system and "after the meter" end uses of gas. The Peischl et al. study (2) found a central estimate of $2 \%$ leakage of gas consumed in the region. The Peischl study notes some confounding with geologic seeps (e.g., La Brea tar pits in Los Angeles). Because we consider geologic seeps elsewhere in the second text chart, we do not include these sources here. We consider the Wennberg et al. emissions rates as our "high emitting" distribution and consumption system rate.

No data are available on the fraction of gas consumption that occurs at the "high emitting" gas distribution and consumption systems. The SoCAB was responsible for $\sim 4.3 \%$ (992 BCF) of total U.S. end-use gas consumption in 2008 (see Data File S1). The second text chart plots three exploratory prevalence cases: 
- Low: $1 \%$ of gas consumption occurs from "high emitting" distribution and consumption systems

- Medium: $10 \%$ of gas consumption occurs from "high emitting" distribution and consumption systems

- High: $25 \%$ of gas consumption occurs from "high emitting" distribution and consumption systems

These three cases result in excess emissions of 0.1 to $3.1 \mathrm{Tg} \mathrm{CH}_{4} /$ year above EPA GHGI emissions. These Low, Medium and High cases for excess downstream emissions are plotted as points $a, b, c$ in the "NG distribution and use" bar in the second chart in the main text.

Given the high leakage rates estimated in these studies, we consider it unlikely that a majority of consuming regions have effective leakage rates at the "high emitter" rate. For this reason, we do not explore cases with higher prevalence of these leakage rates.

\subsubsection{Excess petroleum production emissions}

Petroleum production emissions of $\mathrm{CH}_{4}$ are classified as petroleum sector emissions in the EPA GHGI, even though a significant fraction of U.S. NG is produced from "oil" wells.

Peischl et al. (2) examine emissions from production operations in the SoCAB. SoCAB is primarily an oil-producing region: $98 \%$ of the NG produced in the region is oil-associated gas (42). Therefore, emissions from production of gas in the region provide insight on $\mathrm{CH}_{4}$ emissions from petroleum production.

Peischl et al. estimate a leakage rate of $17 \%$ of the gas produced in the basin (range of $14 \%$ to $20 \%$ ) (2). Peischl et al. also note that a California Air Resources Board (CARB) survey estimated leakage rates in the SoCAB basin of $12 \%$ of the gas produced (2). To create illustrative scenarios, we assume leakage of $17 \%$ of the associated gas produced for "high emitting" oil fields with associated gas production.

No data are available on the prevalence of "high emitting" oil fields. It is known that SoCAB was responsible for $0.007 \mathrm{TCF}$ of gas production, which is $\sim 0.1 \%$ of total U.S. associated gas production of 5.91 TCF in 2011. The second text chart plots three exploratory prevalence cases:

- Low: 1\% of associated gas production occurs from "high emitting" oil fields

- Medium: 10\% of associated gas production occurs from "high emitting" oil fields

- High: $25 \%$ of associated gas production occurs from "high emitting" oil fields

These cases are meant to "benchmark" emissions rates at tangible levels, and no data exist to assign a probability to one or more of these cases. These three cases result in excess emissions above EPA GHGI estimated petroleum production emissions of 0.1 to 
3.7 Tg CH 4 /year. Given the very high leakage rates estimated in the Peischl study, we consider it unlikely that a significant fraction of oil fields emit at this "high emitter" rate.

These Low, Medium and High cases for excess petroleum production emissions are plotted as points $a, b, c$ in the "Petroleum production" bar in the second chart in the main text.

\subsubsection{Hydraulic fracturing for NG}

Hydraulic fracturing of $\mathrm{NG}$ has been examined as a potentially large source of $\mathrm{CH}_{4}$ emissions $(41,43,44)$. Recent EPA GHGI modifications have also focused on shale gas emissions $(17,31)$. Emissions during the well completion flowback period are a chief concern.

EPA estimates that net emissions in 2011 from hydraulic fracturing of NG wells (shale gas, tight gas, or any other hydraulically fractured well) were $0.796 \mathrm{Tg}_{\text {of }} \mathrm{CH}_{4}$. Because they estimate that 8077 wells were hydraulically fractured in 2011 , this amounts to a perwell net emissions rate of $98.7 \mathrm{Mg} \mathrm{CH}_{4}$ per well. Note: this value is different from the per-region emissions factors per well (as reported in EPA 2011/2013 GHGI Annex 3) because these net emissions subtract any reductions associated with green completions technologies or other voluntary reductions programs reported to EPA.

O'Sullivan and Paltsev compute two cases for flowback emissions in the 5 major shale gas plays in 2010 (41). He estimates a drilling-weighted "current practice" emissions rate of $54.6 \mathrm{Mg} \mathrm{CH}_{4} /$ well (including $\mathrm{CO}_{2}$ as $\mathrm{CH}_{4}$ eq.). He also estimates an "all venting" case, where no green completions technologies or flaring is applied, of $228.5 \mathrm{Mg} \mathrm{CH}_{4} / \mathrm{well}$. Because O'Sullivan only focuses on the 5 major shale plays, he estimates a smaller number of wells completed than EPA (3948 wells in 2010).

Howarth et al. $(43,44)$ estimate emissions during flowback, but do not compute total emissions for completed wells in a year, nor do they state the prevalence of wells completed using a particular method (e.g., all flowback vented, as they estimate). This makes the Howarth et al. results non-comparable to EPA GHGI EFs.

We estimate two cases for hydraulic fracturing of shale gas wells: shale gas wells in the 5 major shale gas plays, and all hydraulically fractured NG wells. In 2012 New Source Performance Standards (NSPS) for this source category began to be phased in. Therefore, it is unlikely, going forward from 2012 that these sources will be major contributors.

\subsection{All hydraulically fractured NG wells}

To estimate emissions from all hydraulically fractured gas wells (i.e., ones from the 5 largest plays included above plus all other shale as well as tight gas fractured wells), we perform sensitivity analysis on the EPA net emissions rate per hydraulically fractured well. EPA average net $\mathrm{CH}_{4}$ emissions per hydraulically fractured well were $98.7 \mathrm{Mg}$ 
$\mathrm{CH}_{4} /$ well. Our sensitivity cases multiply this emissions rate by an illustrative factor of 0.5 and 2 for low and high cases, respectively. Note that these emissions rates of 49.3 and 197.4 $\mathrm{Mg} \mathrm{CH}_{4} /$ well are similar in scale to the "current practice" and "all venting" cases for shale gas plays noted in O'Sullivan (41), and are deemed to be reasonable bounds on uncertainty with respect to flowback venting emissions.

These low and high bounds are applied to all wells hydraulically fractured in the EPA 2011 GHGI (8077 wells) resulting in excess emissions with respect to the EPA GHGI of $-0.4 \mathrm{Tg} \mathrm{CH}_{4}$ and $0.8 \mathrm{Tg} \mathrm{CH}_{4}$ in the low and high cases, respectively. These results are plotted as results $d$ and $e$ in the second chart in the main text.

\subsection{Shale gas wells in 5 major shale gas plays}

The HDPI database suggests that a total of 4012 wells in the 5 major shale gas plays were completed in 2011 (see above for method of data gathering from HDPI database). To estimate emissions from these wells, we assume that O'Sullivan's (41) estimates of flowback emissions intensity per well from 2010 are applicable to 2011.

The low case applies O'Sullivan's estimate for the "current practice" case, while the high case applies O'Sullivan's estimate for the "all vented" case. These per-well intensities (weighted by completions) equal 56.0 and $234.0 \mathrm{Mg} \mathrm{CH}_{4} /$ well.

Applying these completions emissions intensities to the number of wells assumed drilled in the 5 major shale gas plays in 2011 (4012 wells), while assigning EPA default intensity to other hydraulically fractured wells, we arrive at excess emissions of -0.17 and $0.51 \mathrm{Tg}$ $\mathrm{CH}_{4} /$ year in the low and high cases, respectively. These results are plotted as points $f$ and $g$ in the second chart in the main text. Note that a negative "excess" relative to the EPA GHGI can exist as the lower bound if the alternative emissions estimate is lower than the EPA estimate.

\subsubsection{Sources that are not included in EPA GHGI}

The second chart in the main text includes three sources that are not included in EPA $\mathrm{CH}_{4}$ inventories, but which could be mistaken for NG emissions by chemical or isotopic composition. These sources include and hydraulic fracturing of oil wells (e.g., shale oil wells), abandoned oil and gas wells, and geologic seeps.

\subsection{Hydraulic fracturing of oil wells}

EPA does not include hydraulic fracturing of oil wells in the GHGI. Activity data for hydraulic fracturing of oil wells are taken from the two largest shale oil plays, the Bakken and the Eagle Ford plays. Also included are completions in the Permian basin of TX. The Barnett play is not included in this portion of the analysis (reflecting tight-oil emissions) because it is largely a gas-bearing play. 
Well data were captured from the Drilling Info HPDI database on August 22nd, 2013 (40). Filters were applied to identify wells for analysis. In both the Eagle Ford and Bakken plays, all new production wells are horizontal. In the Permian, new production wells are both horizontal and vertical owing to the fact that in many cases Permian wells target "tight sand formations," where a vertical trajectory is optimal. To generate an upper bound estimate of emissions, it is assumed that all new oil wells in the three analyzed plays are completed using hydraulic fracture stimulation.

Filters applied by play include:

All plays:

- Well production status: Active

- Completion year: 2010 or 2011

- First production year: 2011

Eagle Ford:

- Basin: TX \& LA Gulf Coast Basin

- Reservoir: Eagle Ford, Eagle Ford Shale, Eagle Ford-1, Eagle Ford-2, Eagleford, Eagleford Shale

- Well production type: Oil

- Drill type: Horizontal

Bakken Well Details

- Basin: Williston

- Reservoir: Bakken

- Well production type: Oil (MT wells), and Oil \& Gas (ND wells)

- Drill type: Horizontal

Permian Well Details

- Basin: Permian

- Reservoir: Trend Area (Spraberry), Wolfcamp and assoc., Bonespring and assoc., Yeso and assoc., Glorieta and assoc.

- Well production type: Oil

- Drill type: All

A total of 2969 wells were completed in these plays in 2011. Potential flowback emissions from these tight oil wells are estimated using the method of O'Sullivan (41). Peak gas production (typically first month of production) is converted to a daily initial production (IP) rate. Production during flowback is assumed to increase linearly with time for 9 days prior to IP. "Potential emissions" estimates assume all flowback emissions are vented. Because of productivity differences between wells and varying gasoil-ratios, each play has a different per-well potential flowback emissions rate. Per-well emissions rates were found to be 31.1, 90.9 and $31.2 \mathrm{Mg} \mathrm{CH}_{4} /$ well, respectively, in the Bakken, Eagle Ford, and Permian basins. 
The resulting emissions estimate for this source is computed as the number of wells completed multiplied by the per-well potential emissions. Total potential emissions are $\sim 0.12 \mathrm{Tg} \mathrm{CH}_{4} /$ year for 2011. This emissions rate is plotted as point $h$ in the second chart in the main text. Any reduced emission completion technologies applied would result in lower emissions than this. No activity data are available for use of RECs for oil well fracturing, so none are assumed in this assessment.

\subsection{Abandoned oil and gas wells}

Abandoned oil and gas wells represent conduits to hydrocarbon bearing formations. If these conduits were not properly sealed upon abandonment, then leakage from formations could be occurring. From 1859 to $2009,3.74 \times 10^{6}$ oil and gas wells were drilled in the United States (36-38). As of 2009, some 825,000 oil and gas wells were operating in the United States (39). This implies that $\sim 3 \times 10^{6}$ non-operating (abandoned and plugged) oil and gas wells exist in the United States.

No empirical data was found to characterize leakage rates from abandoned oil and gas wells. For this reason, we perform an order of magnitude exploration. We vary average per-well gas leakage rates of $0.1 \mathrm{MCF} /$ year to $100 \mathrm{MCF} /$ year and gas compositions equal to EPA default production composition (31). This results in U.S. emissions rates between $\sim 0$ and $4.7 \mathrm{Tg} \mathrm{CH}_{4} /$ year. While emissions at the high end of this range seem implausible, this uncertainty cannot be reduced further without empirical studies. The total emissions rates associated with 1,10 , and $100 \mathrm{MCF} /$ well/year are plotted as points $i, j, k$ in the second chart in the main text.

\subsection{Natural geologic seeps}

Geologic seeps occur in all hydrocarbon-bearing sedimentary basins $(34,35)$. To estimate a potential magnitude of $\mathrm{CH}_{4}$ emissions from geologic seeps, we make the following assumptions:

- We include emissions from mud volcanoes, other macro-seeps, micro-seeps, and geothermal vents. Because we are interested in terrestrial sources, we do not include $\mathrm{CH}_{4}$ emissions from oceanic seeps. Best estimates of global emissions from these sources ranges from 21.5-44.3 $\mathrm{Tg} \mathrm{CH}_{4}$ year (35).

- We scale global emissions by the U.S. fraction of Earth's surface area. The United States represents $6.6 \%$ of Earth's terrestrial surface area $\left(9.8 \times 10^{6} \mathrm{~km}^{2}\right)$. We scale terrestrial seeps by this ratio, arriving at 1.4 to $2.9 \mathrm{Tg} \mathrm{CH}_{4} /$ year.

This range of 1.4 to $2.9 \mathrm{Tg} \mathrm{CH}_{4} /$ year is plotted as points $l$ and $m$ in the second chart.

For comparison, Miller et al. (6) estimate that geologic seeps could represent an overall uncertainty of $5 \%$ on their estimated $\mathrm{CH}_{4}$ emissions, or $2.1 \mathrm{Tg} \mathrm{CH}_{4} /$ year. Regional variability in seeps is likely large, and is poorly understood. It is possible that the United States has a larger fraction of Earth's geologic seeps, because of its extensive sedimentary basins. 


\subsubsection{Calculating leakage percentages associated with possible NG leakage}

Given the estimated U.S. national excess emissions from the second chart (main text) of 7-21 $\mathrm{Tg} \mathrm{CH}_{4} /$ year, we can put bounds on the possible leakage rates from the NG system. First, current EPA GHGI estimates for leakage in 2011 are $1.8 \%$ of end use consumption or $1.4 \%$ of gross gas withdrawals (see SI spreadsheet). This amounts to $6.9 \mathrm{Tg} \mathrm{CH}_{4}$ emitted in 2011. If all excess $\mathrm{CH}_{4}$ is due to the NG industry, and the excess NG leakage has a similar molar $\mathrm{CH}_{4}$ fraction as the current leakage profile, then excess emissions of 7-21 $\mathrm{Tg} \mathrm{CH}_{4} /$ year correspond to total emissions of 2 to 4 times GHGI estimates for the $\mathrm{NG}$ industry (e.g., $14-28 \mathrm{Tg} \mathrm{CH}_{4} /$ year).

Removing sources that are known not to be in the GHGI, but measured in atmospheric observations (wild ruminants, and termites) the unexplained excess decreases to 6.8 to $20.8 \mathrm{Tg} \mathrm{CH}_{4} /$ year, or yields an excess percentage leakage of $1.8 \%$ to $5.4 \%$ of end use gas. Coupled with the current estimate of $1.8 \%$ leakage of end use gas consumed, this generates a high-end estimate of $7.1 \%$ gas leakage (on an end use basis). This worst-case scenario is unlikely: it would require all excess $\mathrm{CH}_{4}$ to come from the NG industry, and require total excess at the high end of the observed range from national-scale studies.

Modeling has shown climate benefits from coal to NG switching for power generation over all time periods (i.e., starting immediately) if the well-to-power-plant leakage rate is below $3.2 \%$, while benefits are seen over a 100 year period if leakage is below $7.6 \%$ (28) Therefore, available evidence suggests climate benefits from NG substitution for coal in the power sector over a 100-year assessment period. Alvarez et al. (28) found benefits from NG use in transport at leakage rates below $1.7 \%$ to $3.8 \%$ for 100 year assessment periods (gasoline and diesel substitution, respectively). Therefore, some scenarios appear to support use of NG in passenger vehicle gasoline displacement, but benefits from diesel substitution in heavy-duty trucking are less likely.

Uncertainties about the role of $\mathrm{CH}_{4}$ in climate forcing (46) imply a need for reassessment of these decision points as knowledge improves. This includes updating of the framework developed in Alvarez et al. (28) based on recently increased global warming potential of $\mathrm{CH}_{4}$ reported in the early publication version of the Intergovernmental Panel on Climate Change 5th Assessment Report.

The calculations reported in this section are recorded in the Data File S1, "Calc - Fuel switching" worksheet. 


\section{Supplementary text}

This supplementary text describes in more detail some points of discussion from the main text. The order of discussion follows that of the main text: top-down studies; bottom-up studies and inventories; and policy and decision-making implications.

\subsection{Top-down studies of $\mathrm{CH}_{4}$ emissions}

Top-down studies of $\mathrm{CH}_{4}$ fluxes use atmospheric observations of $\mathrm{CH}_{4}$ concentrations combined with modeling to infer emissions of $\mathrm{CH}_{4}$. The strength of the top-down method is the direct observation of the end product of concern (atmospheric $\mathrm{CH}_{4}$ ), whereas the challenges associated with the top-down method lie in accurately representing atmospheric transport and attributing $\mathrm{CH}_{4}$ to specific sources.

The central challenge in using atmospheric observations to infer emissions is to quantify the link between the observable (dry air mole fraction of $\mathrm{CH}_{4}$ ) and the quantity of interest (spatial distribution of surface mass emission of $\mathrm{CH}_{4}$ per unit time). Atmospheric transport is the end result of complex, nonlinear, multi-scale dynamical processes, presenting a challenge for accurate simulation and observation at sufficient spatial scales and density. Studies approach this problem in different ways.

\subsubsection{Transport box models (mass balance models)}

Some studies $(1,9,47,48)$, have used variations of a simple box model or mass balance model to estimate $\mathrm{CH}_{4}$ fluxes. These models do not rely on simulated wind fields, and instead make measurements of $\mathrm{CH}_{4}$ upwind and downwind along concentration gradients and utilize assumptions about transport. A few examples are explained below to provide further insight into this approach.

Katzenstein et al. (9) collected data from two ground sampling campaigns from September 2001 to May 2002. Samples were analyzed for $\mathrm{CH}_{4}$ and higher hydrocarbons. A simple box model based upon assuming a ventilation time and boundary layer height was used to estimate $\mathrm{CH}_{4}$ emissions of $4-6 \mathrm{Tg} /$ year. They note that the U.S. NG industry was estimated to have emissions of $6 \pm 2 \mathrm{Tg}$ of $\mathrm{CH}_{4}$ per year at this time. Weighting the sample area emissions by either the fraction of the nation's NG produced in Kansas, Oklahoma and Texas (37\% of NG production), or by those states plus the Gulf of Mexico offshore production (62\%), one can calculate that the measured $\mathrm{CH}_{4}$ emissions are 1.64.7 times the EPA GHGI estimate (KA, OK, TX) or 0.9-2.8 times the EPA GHGI estimate (KA, OK, TX, GOM).

Mays et al. (48) performed measurements around the city of Indianapolis by flying the perimeter of the city and comparing upwind and downwind $\mathrm{CH}_{4}$ concentrations. They found elevated $\mathrm{CH}_{4}$ concentrations relative to $\mathrm{CO}_{2}$ concentrations, at orders of magnitude 
larger than the ratios would be if incomplete combustion were the cause. This implies that $\mathrm{CH}_{4}$ is derived "mostly from noncombustion sources" such as landfills, NG leakage and wastewater treatment. No more specific source attribution was possible with this model.

Karion et al. (1) recently used a mass-balance approach to estimating emissions from a NG field in North East Utah (Uintah basin). Their approach involved flying upwind and downwind transects near the gas field, with wind direction and velocity measurements used to integrate emissions across the horizontal plume downwind of the source. The resulting emissions determined from this flight were $6.2-11.7 \%$ of the gas production in the basin on the day of measurements.

The simple box model approach is appealing in that assumptions are straightforward, but large uncertainty ranges are a consequence of these straightforward assumptions, so uncertainty ranges of $50 \%$ or greater are the norm.

\subsubsection{Tracer-tracer approaches}

Tracer-tracer approaches also do not rely on simulated wind fields. Instead, a gas with more-precisely quantified emissions (gas A) than the gas of interest (gas B) is exploited to estimate emissions of gas B. If sources for A and B are co-located, or sufficient mixing has occurred between the point of emission and the point of measurement, the observed slope of the concentration of the two gases can be convolved with inventory estimates of emissions of gas A to produce an estimate for gas B. This approach assumes that: 1) emissions of gas A are well known, 2) the gases of interest are sufficiently well mixed, and 3) that atmospheric processes affect both gases equally.

Multiple studies have been performed to date in the Los Angeles basin using these approaches $(7,9,10,12)$. These tracer-tracer approaches have similarities with tracer methods applied at smaller scales with purposefully released tracers like $\mathrm{SF}_{6}(49)$. Numerous studies of this type were performed in the 1990s, including a number of studies to support the EPA/GRI study (50).

Wennberg et al. use the California Air Resources Board (CARB) carbon monoxide (CO) inventory to scale $\mathrm{CH}_{4}$ concentrations measured via aircraft in 2008 and 2010. Samples from the Mt. Wilson observatory and total air column concentrations from Wunch et al. (12) were also used. Wennberg et al. estimate $\mathrm{CH}_{4}$ fluxes of $0.38 \pm 0.1 \mathrm{Tg} /$ year to $0.47 \pm$ $0.1 \mathrm{Tg} /$ year [table 2 in (7)]. These estimates can be compared to South Coast Air Quality Management District sector-based inventories of $0.212 \mathrm{Tg} / \mathrm{year}$ [table 3 in (7). Uncertainty is introduced into these methods by the uncertainty in the tracer gas inventory (CO emissions rates $\pm 10 \%$, included in above uncertainty ranges) [p. 9286 in (7)].

Wennberg et al. also examined $\mathrm{C}_{2} \mathrm{H}_{6}$ concentrations along with ratios of $\mathrm{C}_{2} \mathrm{H}_{6}$ to $\mathrm{CH}_{4}$ in gas sold over the study time period. The bottom-up $\mathrm{CH}_{4}$ inventory accounts for $35-73 \%$ of excess $\mathrm{CH}_{4}$ emissions, but only $15 \%$ of the excess $\mathrm{C}_{2} \mathrm{H}_{6}$. A NG source of $0.23 \mathrm{Tg}$ with 
$\mathrm{a} \mathrm{C}_{2} \mathrm{H}_{6}: \mathrm{CH}_{4}$ ratio of $2.6 \%$ (similar to pipeline gas composition of $2.09 \%$ ) simultaneously closes both of these budgets. Wennberg et al. note that the similar time trend in pipeline $\mathrm{C}_{2} \mathrm{H}_{6}: \mathrm{CH}_{4}$ ratio and observed atmospheric $\mathrm{C}_{2} \mathrm{H}_{6}: \mathrm{CH}_{4}$ ratio are further suggestive of pipeline gas being responsible for the majority of the observed atmospheric signal.

An earlier study by Wunch et al. (12) used Fourier transform spectroscopic (FTS) analysis to determine concentrations of $\mathrm{CO}_{2}, \mathrm{CO}, \mathrm{CH}_{4}$ and $\mathrm{N}_{2} \mathrm{O}$. Correlations between concentrations of these species are used, along with $\mathrm{CO}_{2}$ emissions from EDGAR and $\mathrm{CARB}$ inventories for the region, to estimate the fluxes of the other gases. They estimate $0.6 \pm 1 \mathrm{Tg} \mathrm{CH}_{4}$ per year. A similar approach using the CARB CO inventory to scale the flux arrives at a $\mathrm{CH}_{4}$ flux of $0.4 \pm 0.1 \mathrm{Tg} /$ year, in agreement with Wennberg et al. above. Wunch et al. then scale the CARB $\mathrm{CH}_{4}$ inventory to the South Coast Air Basin (SoCAB) by population (after removing emissions from agriculture and forestry, which are

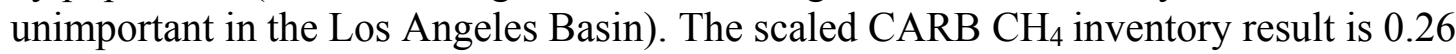
$\mathrm{Tg} /$ year, significantly below either inferred FTS result that uses $\mathrm{CO}_{2}$ or $\mathrm{CO}$ as the tracer.

Finally, a study by Hsu et al. (10) used data from the Mt. Wilson observatory and the CARB CO inventory to estimate $\mathrm{CH}_{4}$ fluxes in the region. They arrive at a result of $4.2 \pm$ $0.12 \mathrm{MMT} \mathrm{CO}_{2}$ eq./year, which can be compared to a spatially disaggregated CARB inventory for the region of 3.0 $\mathrm{MMT} \mathrm{CO}_{2}$ eq/year. Uncertainty arises in this study due to the limited spatial representation of the sampling and because the CARB bottom-up $\mathrm{CH}_{4}$ inventory (used for comparison) is extrapolated from a 2004 inventory. As such, the study finds good agreement between the top-down estimate (derived from the observed $\mathrm{CH}_{4} / \mathrm{CO}$ slope \& $\mathrm{CO}$ inventory) and the bottom-up $\mathrm{CH}_{4}$ inventory, even though under and/or un-inventoried sources may be present.

Numerous Los Angeles studies use $\mathrm{CO}$ as the tracer gas. As a consequence of addressing air quality problems, $\mathrm{CARB}$ has refined the $\mathrm{CO}$ inventory annually and the uncertainty in this inventory is considered to be small (best guess $\sim 10 \%$ ), compared with the $\mathrm{CH}_{4}$ inventory. The usage of a tracer such as $\mathrm{CO}$ helps circumvent the need to directly represent atmospheric transport. It does however convolve the resulting top-down answer with a bottom-up inventory. For example, in the Wunch et al. study, $\mathrm{CH}_{4}$ emissions differ by as much as $50 \%$ if a different $\mathrm{CO}_{2}$ inventory is used (12).

In another study region, Pétron et al. (3) use alkane signatures to estimate emissions from the NG industry in the Denver-Julesberg basin of Northeastern Colorado. Emissions of 129.6 $\mathrm{Gg} \mathrm{CH}_{4} /$ year $(71.6$ - $251.9 \mathrm{Gg}$ ) were estimated for the region, in comparison to 64.3 (46 - 86) $\mathrm{Gg} \mathrm{CH}_{4}$ estimated in a regional inventory. This study employs a tracertracer method, leveraging inventory estimates of higher $\mathrm{HC}\left(\mathrm{C}_{3} \mathrm{H}_{8}\right)$ emissions along with gas emissions composition profiles to estimate a $\mathrm{CH}_{4}$ source from observed $\mathrm{CH}_{4}$ and $\mathrm{C}_{3} \mathrm{H}_{8}$. Observations were generated using a tall tower and ground-based sampling. There has been controversy associated with this study $(25,32)$, which is discussed below. Note that the Pétron attribution to oil and gas emissions is further supported by studies which attribute VOCs in the region of the Boulder Atmospheric Observatory tower largely to oil and gas activities (e.g., $72 \%$ of $\mathrm{C}_{2} \mathrm{H}_{6}$ and $90 \%$ of $\mathrm{C}_{3} \mathrm{H}_{8}$ in the region) (51). 
Tracer release studies developed in the 1990s to estimate emissions across a facility use a similar approach with similar assumptions $(49,52,53)$. In this case, the tracer is purposely released, and is a gas species that is (a) easily detected, and (b) present at essentially no background concentration. In these studies $\mathrm{SF}_{6}$ was chosen as the tracer gas. The tracer gas is released in the same vicinity as the suspected gas leaks, and the concentrations of the two gases are measured downstream in the plume after sufficient atmospheric mixing has occurred between the two sources.

\subsubsection{Transport inversion modeling}

Using full simulations of atmospheric transport (wind fields), observed concentrations can be linked to fluxes. The sensitivity of an observation to a given location's flux can be calculated, and then an inverse modeling approach can be employed - either to scale a prior emissions field (Bayesian inversion) or to derive fluxes from observations and predictor variables (Geostatistical inversion).

A number of studies have been performed on $\mathrm{CH}_{4}$ in North America using atmospheric inversion $(5,6,8,9)$. Kort et al. (5) used data from a campaign of 38 flights undertaken in 2003. Approximately 300 flask samples were acquired and concentrations were measured for a number of species, including $\mathrm{CH}_{4}$. The resulting concentration data (e.g., 300 data points) were combined with a time inverted transport model to simulate the transport of air parcels. This modeling technique explicitly links the observed concentrations with surface fluxes. Spatial emissions inventories (EDGAR) are used to initialize sources in the model, and a Bayesian inversion is performed. The model and measurements provided strong constraints on continental-scale emissions but did not have the resolution to distinguish different sources of $\mathrm{CH}_{4}$ or to examine regional scale inventories. Good agreement was found with the EDGAR v3.2 2000 inventory (5, 6), but emission rates were higher than in the EPA GHGI and the updated EDGAR v4.1 inventory (6).

More recently, Miller et al. (6) used a two year record of observations $(\sim 12000$ observations from aircraft and tall towers) spanning most of the United States with a geostatistical approach to estimate $\mathrm{CH}_{4}$ fluxes with less reliance on prior inventory spatial distributions. A version of the inverse model that used the EDGAR spatial emissions dataset found the emissions to be too low and the spatial representation to be incorrect. With the high-resolution geostatistical approach Miller et al. find significant underestimation of emissions of $\mathrm{CH}_{4}$ from the south-central United States. Also, Miller et al. use alkane $\left(\mathrm{C}_{3} \mathrm{H}_{8}\right)$ data from aircraft measurement to help partition excess $\mathrm{CH}_{4}$ in the region between fossil fuel extraction, livestock and other sources.

These two studies $(5,6)$ used different datasets [aircraft transecting North America for (5), tall-towers and vertical profiling aircraft for (6)], for different years (2003 and 2008), with different spatial coverage, and used different inversion techniques [Bayesian for (5), Geostatistical for (6)]. Despite these differences, both top-down methods found similar emission rates (35.11 \& 32.4 Tg C/year), substantially larger than EDGAR v4.2 or U.S. EPA GHGI emissions estimates. 
Xiao et al. (8) used a global chemical transport model to model the global emissions inventory for $\mathrm{C}_{2} \mathrm{H}_{6}$. $\mathrm{C}_{2} \mathrm{H}_{6}$ concentrations from dozens of sampling campaigns from 1989 to 2004 were input to the model. Using results from the U.S. region (U.S. $\mathrm{C}_{2} \mathrm{H}_{6}$ emissions estimated at $2.4 \mathrm{Tg} /$ year), as well as U.S. GHGI results, Xiao et al. examine whether $\mathrm{CH}_{4}$ emissions inventories are likely to be accurate. Given an approximate inventory emissions rate of $10 \mathrm{Tg} \mathrm{CH}_{4}$ /year from the EPA GHGI, they find that the related $\mathrm{C}_{2} \mathrm{H}_{6}$ emissions should be 1.2 to 2.5 times lower than observed [table 4 in (8)]. Thus, $\mathrm{C}_{2} \mathrm{H}_{6}$ measurements, which cannot be attributed to biogenic sources, imply larger $\mathrm{CH}_{4}$ emissions than calculated in the EPA GHGI.

The largest source of uncertainty in transport modeling is typically representation of transport. In particular, bias errors in features such as boundary layer height can directly map into flux fields. This can result in a high fidelity (narrow error-bar) answer with potentially larger bias errors.

\subsubsection{Approaches for source attribution}

Attributing the $\mathrm{CH}_{4}$ observed in measurements to NG production is challenging. A variety of approaches have been proposed to overcome these attribution challenges: isotopic measurements; alkane fingerprints; and proximity and flux direction.

Townsend-Small et al. (11) sampled air near multiple $\mathrm{CH}_{4}$ sources (e.g., power plants, oil fields, landfills). $\delta^{13} \mathrm{C}$ and $\delta \mathrm{D}$ (deuterium) values for $\mathrm{CH}_{4}$ were collected for these exhaust streams [table 1 and figure 2 in (11)]. Extrapolating from measured data to pure $\mathrm{CH}_{4}$ isotopic ratios suggests ratios of $\delta^{13} \mathrm{C} \approx-41.5$ and $\delta \mathrm{D} \approx-203$ to -228 . The authors suggest that these ratios are in the range of those observed in oil fields, refineries and power plants. The number of samples in the study is small, and correlations are weak [e.g., Figure 4 in (11)]. The largest limitation to isotopic attribution is instrumentation. With small enhancements of the ambient $\mathrm{CH}_{4}$ background, there are only very small perturbations to the isotopic signature, and present instrumentation is challenged to detect this. This study was unable to distinguish between natural geologic $\mathrm{CH}_{4}$ or $\mathrm{CH}_{4}$ from refineries, $\mathrm{NG}$, or oil refining.

A debate over the Pétron et al. study $(3,25,32)$ centers on assumptions made in convolving inventory estimates of emissions, and the composition of such emissions, with atmospheric observations to produce estimated emissions of $\mathrm{CH}_{4}$. Two conclusions can be drawn from this discussion: first, alkane signatures robustly indicate the presence of $\mathrm{CH}_{4}$ from NG; and second, convolving top-down methods with bottom-up methods entrains bottom-up uncertainty into the top-down estimate. Without robustly superior inventory information (such as for $\mathrm{CO}$ emissions in California) such a convolution is not definitive.

Another method to address the problem of attribution is to use alkane signatures to constrain the sources of emissions. In simple terms, biological systems produce $\mathrm{CH}_{4}$ in anaerobic metabolic pathways, but no comparable large-scale production pathways exist 
for $\mathrm{C}_{2} \mathrm{H}_{6}$ and $\mathrm{C}_{3} \mathrm{H}_{8}$. Xiao et al. use global $\mathrm{C}_{2} \mathrm{H}_{6}$ measurements in this way (8). Wennberg et al. (7) use $\mathrm{C}_{2} \mathrm{H}_{6}$ to constrain $\mathrm{CH}_{4}$ emissions in the LA basin, and find that this strongly suggests that the missing $\mathrm{CH}_{4}$ source is fossil in origin. Katzenstein et al. use a complete $\mathrm{HC}$ signature with higher $\mathrm{HCs}$ of various types, which point to a fossil source for $\mathrm{CH}_{4}$ over the south-central United States (9). At large scales, Miller et al. argue that continental-level $\mathrm{CH}_{4}$ to $\mathrm{C}_{3} \mathrm{H}_{8}$ ratios imply a fossil source for the excess $\mathrm{CH}_{4}(6)$.

Lastly, $\mathrm{CH}_{4}$ can be attributed to sources in some study designs by simple proximity (spatial and/or temporal). That is, $\mathrm{CH}_{4}$ observed near a given facility can be assumed to be emitted from that facility. Such attribution was used to eliminate dairy farm emissions from ARCTAS flight data in the Wennberg et al. study (7). Similar results have been found in NOAA driving campaigns (3) and in calibrating isotopic signatures to sources of various types (11). This approach was also used in recent work in the Uintah basin to distinguish oil-associated $\mathrm{CH}_{4}$ from natural-gas-derived $\mathrm{CH}_{4}$ (45).

\subsubsection{Uncertainty in top-down measurements}

\subsubsection{1 $\mathrm{CH}_{4}$ measurement uncertainty}

Most $\mathrm{CH}_{4}$ observations made in studies analyzed here are made either via whole air flask samples measured in the lab by gas chromatography (5), direct absorption spectroscopy (such as used in aircraft), or spectroscopy of an air column [such as in (12)]. Flask samples and direct absorption spectroscopy typically have accuracies of $2 \mathrm{ppb}$ or better (1-sigma), and upward-looking FTS observations of $3.5 \mathrm{ppb}$ (1-sigma). These measurement uncertainties do not have substantial impact on the overall uncertainty of flux estimations made employing these observations.

\subsubsection{Overall assessment of source flux computation uncertainty}

Quantitative simulation of atmospheric transport represents the main source of uncertainty in top-down methods. Recent studies have endeavored to minimize this problem by combining surface and tower measurements with aircraft profiles and total column observations. The column concentration data provide a direct measure of the total mass of $\mathrm{CH}_{4}$ in the atmosphere, and spatial gradients of column amounts define the total mass excess in source regions. On sufficiently large scales (e.g. TX/OK/KS), the flux derived from an inverse model depends on the measurement of this excess and the synoptic scale winds, which are in general well constrained by meteorological data. For example, Miller et al. (6) quote uncertainties of about $12 \%$ for the South-Central region of the United States. Uncertainties in individual flux estimates for smaller regions or less dense samples are larger, $>50 \%$ in some cases.

\subsubsection{Uncertainty in alignment with inventories}


There are challenges in the alignment of atmospheric studies with inventory definitions. For example, oil and gas wells are often located in the same air basin. If oil wells contribute to ambient $\mathrm{CH}_{4}$ concentrations, but all emissions are attributed to $\mathrm{NG}$ activities, then $\mathrm{NG}$ emissions could be significantly overestimated (emissions of $\mathrm{CH}_{4}$ from oil-associated gas production are classified as petroleum sector emissions in the GHGI).

A major hindrance in this area is a lack of understanding of the compositions of produced and sold gases. For example, uncertainties in attribution of $\mathrm{CH}_{4}$ to $\mathrm{NG}$ in Wennberg (7) were dominated by uncertainty in $\alpha$, the ratio of $\mathrm{C}_{2} \mathrm{H}_{6}$ to $\mathrm{CH}_{4}$ in the sold $\mathrm{NG}$ [p. 9287 in (7)]. Some studies attempt to use raw and processed gas compositions to better discern the stage of gas emissions (2). Unfortunately, such methods of attribution depend strongly on the accuracy of gas composition data. Gas composition can vary quite significantly from field to field, as observed in Colorado (3), from California oil fields [figure 3.10 in (54)], and in the Barnett shale (55).

\subsubsection{Other sources of variability or error}

Natural gas emissions are both spatially and temporally variable. Spatial variability can exist at the scale of wells, fields, or "plays" (productive geologic formations). Temporal variability includes emission variations that result from variations in the annual rate of well workovers and well completions and variations in vent times and the number of vents per vented wells.

The impact of temporal variability on top-down studies is not well explored. This is likely to be a larger problem at small scale (e.g., basin or city measurements) than at large scale (due to mixing across days at continental scale that will smooth stochastic variations). Two types of confounding temporal variation could occur. First, there could be correlation between sampling time and emissions times. A significant fraction of recent EPA GHGI emissions came from liquids unloading events. Allen et al. (26) also found significant potential emissions from liquids unloading. Because some of these liquids unloading events are manual or semi-manual in nature, they will tend to be performed more commonly in daylight hours. Also, unloading of condensate from tanks into trucks in liquids-rich plays would likely be similar in their time profiles.

Aircraft measurements are typically performed in the afternoon, because a welldeveloped boundary layer and well-mixed conditions found in afternoons are easier to simulate. Therefore, afternoon measurements might see a larger signal from daytime liquids unloading (or other maintenance) activities. However, this is unlikely for observations that span the whole atmospheric column, for which the turnover time is measured in days. Compressor emissions or drilling rig emissions will tend to be more constant in flux, and would not contribute to this possible distortion (e.g., drilling rigs operate 24 hours per day).

Second, there are emissions occurrences that are one-time or rare, such as venting emissions during well flowback. Since these occur once or a few times in a well's 
lifetime, missing or including this source within a short time of a single aircraft flight could lead to an under or overestimate of emissions. We believe that this is likely to be a small effect because drilling rigs tend to operate on a continuous basis, so in a large basin, there will likely be a relatively steady well completion and flowback rate (e.g., one well completed per day on average). Also, large scale studies such as Kort (7) and Miller (6) have used data from many aircraft flights over extended spatial scales and long time intervals.

Analysis of the variability associated with each of these sources could be addressed by constructing a hierarchical model developed using Bayesian statistics [see, for example (56)]. This approach may be especially useful when data are available from several levels of observational units (e.g., wells, fields, or formations).

\subsubsection{Coverage and representativeness of atmospheric studies}

An important parameter for atmospheric studies included in the first text chart is the coverage of the studies, including both spatial scale and density of measurements. Due to limited sampling funds and efforts, atmospheric studies must rely on a limited number of samples. Thus, regional- and state-level studies tend to have more dense measurements over a smaller area, while national-scale measurements tend to rely on more spatially and temporally sparse measurements taken over a larger area. Table S5 lists all atmospheric studies included in the first text chart, along with their fractional coverage of U.S. gas non-associated gas production and gas consumption. In addition, the number of samples or sampling campaign length and frequency are given for included studies. Large-scale studies cover wide spatial extent (e.g., all United States), with variable fidelity in a given region depending on the local sampling density. For example, see Miller et al. [figure S3 in (6)] for spatial representation of sample coverage. 
Table S5. Atmospheric studies: spatial coverage and sample size

\begin{tabular}{|c|c|c|c|c|}
\hline Study & Region & $\begin{array}{l}\text { Frac. of U.S. } \\
\text { non-assoc. } \\
\text { gas prod. in } \\
\text { study region }\end{array}$ & $\begin{array}{l}\text { Frac. of U.S. } \\
\text { gas cons. in } \\
\text { study region }\end{array}$ & Number of samples \\
\hline Miller et al. & US & $100 \%$ & $100 \%$ & $\sim 12,000$ \\
\hline & South-central US & $45.5 \%$ & $18.5 \%$ & $\begin{array}{l}\sim 900 \text { tower obs. } \\
\text { Flight obs. not given }\end{array}$ \\
\hline Kort et al. & US & $100 \%$ & $100 \%$ & $\sim 300$ \\
\hline Katzenstein et al. & South-central US & $37.7 \%$ & $21.8 \%$ & $\sim 300$ \\
\hline Wang et al. & US & $100 \%$ & $100 \%$ & Not given \\
\hline Xiao et al. & US & $100 \%$ & $100 \%$ & Not given \\
\hline Pétron et al. & $\begin{array}{l}\text { Denver-Julesberg } \\
\text { basin }\end{array}$ & $0.41 \%$ & $0.08 \%$ & $\begin{array}{l}\sim 400-500 \text { tower } \\
\sim 100 \text { ground. }\end{array}$ \\
\hline Wunch et al. & SoCAB & $0.002 \%$ & $4.63 \%$ & $\begin{array}{l}131 \text { days } \\
\text { - Continuous at } 0.5 \mathrm{~Hz}\end{array}$ \\
\hline Hsu et al. & $\begin{array}{l}\text { Los Angeles } \\
\text { County within } \\
\text { SoCAB }\end{array}$ & $0.002 \%$ & $2.97 \%$ & $\begin{array}{l}36 \text { days } \\
\text { - Canisters at } 1 / \mathrm{hr} \\
\text { - Continuous at } 1 \mathrm{~Hz}\end{array}$ \\
\hline Wennberg et al. & SoCAB & $0.002 \%$ & $4.63 \%$ & $\begin{array}{l}\text { See Hsu and Wunch } \\
\text { Additional: } 4 \text { flights }\end{array}$ \\
\hline Peischl et al. & SoCAB & $0.0005 \%$ & $4.32 \%$ & $\begin{array}{l}16 \text { flights } \\
\text { - Continuous at } 1 \mathrm{~Hz} \\
\text { - Flasks, freq. unknown }\end{array}$ \\
\hline Karion et al. & Uintah basin & $1.42 \%$ & $0.01 \%$ & $\begin{array}{l}1 \mathrm{flight} \\
\text { - Continuous at } 0.5 \mathrm{~Hz} \text {. }\end{array}$ \\
\hline
\end{tabular}




\subsection{Bottom-up methods: Inventories and emissions factors}

The U.S. Environmental Protection Agency (EPA) creates a yearly greenhouse gas inventory (GHGI) of $\mathrm{CH}_{4}$ emissions from NG systems (17). The methodology used has been relatively consistent since the 1990s, with the methods outlined in summary form (57) and in a detailed 15 volume report $(14,15,50,58-69)$. The EPA GHGI follows methodologies outlined in Intergovernmental Panel on Climate Change (IPCC) guidelines (70).

The general approach of the EPA GHGI is to generate emissions factors (EFs) for typical sources in each industry segment or stratum. In some cases, EFs are used to generate facility-level emission rates. In all cases, EFs are multiplied by a population (e.g., number of compressors) or activity factor (e.g., SCF transmitted) to develop an emissions rate for a given segment or stratum.

\subsubsection{EPA/GRI study}

\subsubsection{Study timeline and goals}

For the last $\sim 20$ years the EPA GHGI has largely relied upon a detailed study undertaken from March 1991 - June 1996 by EPA and the Gas Research Institute (GRI), with work performed by a number of sub-contractors. The methods are outlined in summary form (58) and in a detailed 15 volume report $(14,15,50,58-69)$. Additional reports were published by GRI, some of which are not currently available for purchase.

The original EPA/GRI study modeled national emissions of $\mathrm{CH}_{4}$ for 1992 at $314+105$ Bscf ( $+33 \%$ at $95 \%$ confidence level). This leakage rate was equivalent to $1.4+0.5 \%$ of gross NG production. Since a key goal of the study was to estimate leakage to $+0.5 \%$ of gross production, the study authors considered the estimate a success.

A major implication of the EPA/GRI study was that NG contributes less to global warming than coal or oil - and that fuel switching is supported as a GHG mitigation method (57).

\subsubsection{Structure of the EPA/GRI study}

The EPA/GRI study (50) included all segments of the NG industry, including: production, gas processing, transportation, storage, and distribution (57). It did not include leakage beyond the consumer or industry meter. Each industry segment was analyzed to determine important equipment types (e.g., separators, glycol dehydrators). Expertise was applied to determine the largest potential sources, and these sources were targeted for more thorough sampling campaigns (15). 
On-site measurements are used to project national emissions from a source by generating EFs. The relevant equation for scaling EFs is as follows:

$\mathrm{E}=\mathrm{EF} \times \mathrm{AF}$

Where $\mathrm{E}$ is emissions from a given source (e.g., $\mathrm{MCF} / \mathrm{year}$ ), $\mathrm{EF}$ is the emissions factor (e.g., MCF/activity) and AF is the activity factor (activities/year). This is a simplification: a variety of structures are used for the activity factor, depending on the industry segment.

Equipment source emissions measurements underlying the EFs were made using a variety of techniques. EPA Method 21 was used in the EPA/GRI device-level studies (50). In Method 21, a correlation technique is used: local $\mathrm{CH}_{4}$ concentration is measured, and this concentration is related to an emission rate by a correlation equation. Correlations are generated with direct flux measurement, tracer gas methods, or leak statistics methods. A major concern with screening techniques is the uncertainty associated with screening correlations $(15,21,60)$. Generally, the instrument used for local concentration measurements is an organic vapor analyzer that uses flame ionization detection (FID), with concentration sensitivity ranges between 10,000 to 100,000 ppmv.

Alternatively, a more labor-intensive technique used was the total enclosure technique (bagging), which can be used to measure the flux over time into an enclosed volume, generating a leakage rate. In bagging, the leaking area is isolated and uncontaminated air is blown through an area containing the component.

EFs were determined from average emissions rates for basic components such as valves, flanges, seals and other connectors (76-80). Nearly 200,000 components were sampled at 33 facilities throughout the country.

The AF is the total number of sources (e.g., number of compressors) or the total amount of infrastructure (e.g., miles of transmission pipeline), in the target population. In some cases, equipment AFs are not well known. To extrapolate equipment activity factors representing regional or national averages, "extrapolation parameters" (EP) are used (57).

\subsubsection{Categories of emissions in EPA/GRI study}

Three main categories of emissions sources were outlined the EPA/GRI (50) study:

1. Vented and combustion sources (purposeful, consistent sources);

2. Blowdown and purge emissions (purposeful emissions, but sporadic and unplanned due to process upsets); and

3. Leaks (so-called "fugitive", or unplanned emissions).

Vented emissions result from devices that vent some fraction of the gas they process. Examples include pneumatic devices, and dehydrator $\mathrm{CH}_{4}$ slippage emissions. Blowdown and purge emissions are a subset of vented emissions. 'Blowdown' refers to venting of gas contained inside a pressure vessel, pipeline, or other piece of equipment. Purge is the process of clearing air from a piece of equipment by displacement with NG. Through 
purging, some NG is emitted along with the air to the atmosphere. Equipment leaks result from malfunctioning or poor operation of equipment and are not part of designed operational profiles. Leaks are estimated using an EF and AF approach by counts of basic components in a facility (e.g., valves, seals).

\subsubsection{Challenges with bias and uncertainty in EPA/GRI study and resulting inventory uncertainty}

Current inventory methods rely on a set of key assumptions: a) samples used to generate device-level EFs are drawn from the same population whose emissions are being estimated; b) samples are of sufficient size to characterize the population, given heterogeneities in technologies and managerial practice; c) leakage volumes are not dominated by abnormal leakage rates or outlier events; d) activity counts are known with reasonable certainty; and e) all major sources of emissions are included in inventories. Current methods do not satisfy these assumptions, with varying degrees of uncertainty existing for each assumption.

\subsection{Challenges with obtaining representative samples}

With regard to the first challenge, the EPA/GRI study (50) authors devoted significant effort into obtaining an unbiased sample when generating EFs. The EPA/GRI methodological papers note that the sampling approach used was not truly random (15, $50,57,60)$. The sampling method used could be biased if:

1. The list of operators used to choose sites was not representative of the population of operators, or if facilities or technologies run by operators were not representative of the population of facilities (e.g., gas type, equipment vintage, equipment type, etc.).

2. The facilities which allowed on-site sampling were not representative of the typical facility;

3. The facilities sampled were altered before testing.

First, the list of operators might not be representative of all operators. A related problem would be if facilities included on sampling list were not representative of the total population of facilities. This problem could be significantly worse in the current day, given a shift in producing regions and producing technologies since the early 1990s (i.e., a list that was originally representative becomes less so over time). Bias in technology vintage may affect current use of EFs. Older equipment has been shown to have higher leak rates. For example, Clearstone et al. (15) found that equipment over 30 years of age had leakage rates over 5 times larger ( $\mathrm{kg}$ of $\mathrm{CH}_{4}$ per MMSCF of gas plant throughput) than equipment under 30 years of age [figure 21 in (15)]. This could lead to bias in current day use of EFs from EPA/GRI (51), even if no such vintage bias existed at the time of the study. In the opposite direction, there is significant new infrastructure in some regions that were not major gas producing regions until the recent shale gas expansion (e.g., Pennsylvania). 
Second, it is possible that facilities which allowed on-site sampling were not representative of the population. All else being equal, it is plausible that operators with effective leak detection and repair programs were more likely to allow EPA-affiliated scientists on site to measure leaks. In the study of pipeline leaks, 30 companies were invited to participate, of which nine agreed to participate, and six eventually provided data [p. 5 in (58)]. Kirchgessner et al. note that "the companies contacted were not required to participate" (58). Also, contacted companies were asked to select a representative site for sampling (15). It is also plausible that companies may have selected sites with less problematic operations.

Third, it is possible that operators, expecting a visit from EPA scientists, might perform a check of their facility for leaks, at least to reduce any obvious large leaks that might pose safety concerns. Because (as shown below), a few large emissions sources generally contribute a significant share of emissions, even cursory "tune up" maintenance performed in anticipation of future sampling could cause significant bias in emissions estimates from the sampled facilities.

Ultimately, the direction and magnitude of sampling bias in the EPA/GRI study cannot be known. The above factors suggest that it is possible that the EPA/GRI samples were taken from a select population with an emissions distribution having a smaller mean rate and less variability (e.g., less likelihood of extreme leakage rates) than the total population. Importantly, this study design would be considered unacceptable in other fields, e.g. observational biomedical research, because of the potential for generating bias.

\subsection{Challenges with sample size requirements}

A fundamental challenge exists in sampling for emissions rates: the NG industry is large and diverse, and sampling is expensive. Given these challenges, the EPA/GRI study made significant sampling efforts (e.g., $>200,000$ sources sampled) that have not been surpassed to date. It was noted in the EPA/GRI study that sample sizes were limited by funding availability.

EFs are ideally defined as the average measured emissions from a large number of randomly selected sources in a source category. Stratification can be applied usefully to mitigate variability due to smaller-than-ideal sample sizes. Stratification reduces the number of samples required to reach a given level of uncertainty. This method was applied extensively in the original EPA/GRI sampling design (20). An example of stratification is given by compressor size: one can segment compressor drivers by the horsepower of the driver, and measure devices in each stratum. However, if reliable AFs are not collected by stratum then stratification does not improve accuracy (e.g., if yearly inventory compilation efforts will not have access to accurate estimates of numbers of compressors operating in each stratum). Stratification may provide additional insights into variability between and within source categories, which is of interest in determining emissions distributions (see below). 


\subsection{Challenges with highly heterogeneous emissions rates}

The distribution of emissions between sources can affect the accuracy of samplingderived EFs (20), independent of other biases in sampling. If total emissions are dominated by a small number of rare high emitters (e.g., "heavy-tailed" distributions), the construction of EFs using simple arithmetic means of the sampled population is problematic. Limited sampling from such distributions to generate a mean emissions rate has a higher probability of underestimating means than overestimating them. This challenge was recognized in the EPA/GRI study (20), but it was thought unimportant.

Evidence suggests that a small percentage of sources can be responsible for the majority of emissions at a given facility $(15,28,72-75)$. For example, the Clearstone report noted that only $2.2 \%$ of sampled components were leaking above the detection limit $(1,629$ out of 74,438 sampled components registered local concentrations above 10,000 ppm). They also report that the largest 10 leaks (i.e., the top $0.013 \%$ of surveyed components) were responsible for $58 \%$ of the gas leakage. Also, Clearstone noted that the "top 10 leaks [at a facility] typically contribute more than $80 \%$ of emissions from leaks", for cases where many thousands of devices were sampled (74), indicating that these outlier-dominated distributions are characteristic.

Table S6 describes the details of various studies with findings of "super-emitting sources" 
Table S6. Evidence of heterogeneity of emissions magnitudes across studies.

\begin{tabular}{|c|c|c|c|c|}
\hline Study name & $\begin{array}{l}\text { Industry } \\
\text { stage }\end{array}$ & $\begin{array}{l}\text { Measurement } \\
\text { technique }\end{array}$ & Degree of heterogeneity noted & $\begin{array}{l}\text { Pages with relevant statistics, } \\
\text { tables, or quotes. }\end{array}$ \\
\hline $\begin{array}{l}\text { Allen et al. } \\
2013\end{array}$ & Production & $\begin{array}{l}\text { Direct measurement } \\
\text { of unloading events }\end{array}$ & "Four of nine events contribute more than $95 \%$ of total emissions" & Article p. 3 . \\
\hline Alvarez 2012 & Production & $\begin{array}{l}\text { Analysis of reported } \\
\text { emissions }\end{array}$ & "10\% of well sites accounted for $70 \%$ of emissions" & $\begin{array}{l}\text { Article p. 3. Also see SI dataset in } \\
\text { Microsoft Excel format. }\end{array}$ \\
\hline $\begin{array}{l}\text { Chambers } \\
2006\end{array}$ & Processing & $\begin{array}{l}\text { Down-wind } \\
\text { differential } \\
\text { absorption LIDAR }\end{array}$ & $\begin{array}{l}\text { "At plant B a single intermittent leak from a pressure relief valve was } \\
\text { located that increased site emissions from } 104 \mathrm{~kg} / \mathrm{hr} \text { to } 450 \mathrm{~kg} / \mathrm{h} \text {." }\end{array}$ & p. 6 \\
\hline $\begin{array}{l}\text { Clearstone } \\
2002\end{array}$ & Processing & $\begin{array}{l}\text { Direct measurement } \\
\text { using Hi-Flow } \\
\text { sampler }\end{array}$ & $\begin{array}{l}>100,000 \text { devices sampled across } 4 \text { facilities. between } 35.7 \% \text { and } 64.6 \% \\
\text { of leakage from each facility was found leaking from top } 10 \text { leaks in each } \\
\text { facility. }\end{array}$ & $\begin{array}{l}\text { Executive summary, Table } 4 \text { (p. } \\
24) .\end{array}$ \\
\hline $\begin{array}{l}\text { Cormack, } \\
2007\end{array}$ & $\begin{array}{l}\text { Transmission } \\
\text { compressors }\end{array}$ & $\begin{array}{l}\text { Direct measurement } \\
\text { with Hi-Flow }\end{array}$ & $\begin{array}{l}\text { Top single leak accounted } 40 \% \text { of leakage. Top } 20 \% \text { of leaking } \\
\text { components accounted for } 80 \% \text { of leakage. }\end{array}$ & Figure p. 15 \\
\hline $\begin{array}{l}\text { Harrison et al. } \\
2011\end{array}$ & $\begin{array}{l}\text { Compressor } \\
\text { stations }\end{array}$ & $\begin{array}{l}\text { IR camera, Hi-Flow } \\
\text { sampler }\end{array}$ & $\begin{array}{l}\text { Reported data in Appendix B show outliers. For example, } \sim 2,800 \text { valves } \\
\text { and flanges were screened with IR camera and } 29 \text { leaks were found. The } \\
\text { single largest of these leaks ( }>1000 \text { mscf/year) is }>100,000 \text { times larger } \\
\text { than valve and flange EF ( } 0.05 \text { or } 0.09 \text { mscf/year). Similar results seen } \\
\text { elsewhere. See, e.g., blowdown line leaks from centrifugal compressors } \\
\text { (table B2) where largest leak represents } 70 \% \text { of the total leakage. }\end{array}$ & See tabular data in Appendix B. \\
\hline $\begin{array}{l}\text { NGML, } \\
\text { Clearstone, } \\
\text { IES } 2006\end{array}$ & $\begin{array}{l}\text { Processing, } \\
\text { well sites, } \\
\text { gathering } \\
\text { compressor } \\
\text { stations }\end{array}$ & $\begin{array}{l}\text { Direct measurement } \\
\text { using Hi-Flow } \\
\text { sampler and optical } \\
\text { methods }\end{array}$ & $\begin{array}{l}>74,000 \text { components sampled. Approx. } 1600 \text { were found to be leaking } \\
\text { ( 2\%). From executive summary: "Repairs to } 10 \text { largest emitting cost- } \\
\text { effective-to-repair components at each site... would reduce natural gas } \\
\text { losses by approximately...58\%" }\end{array}$ & $\begin{array}{l}\text { Executive summary (p. iii). For } \\
\text { details, see Appendix } 1 \text { (separate } \\
\text { PDF) which ranks leaks by } \\
\text { emissions rate for } \sim 1600 \text { leaking } \\
\text { sources. }\end{array}$ \\
\hline Picard, 2005 & All stages & $\begin{array}{l}\text { Sampling via } \\
\text { various methods }\end{array}$ & $\begin{array}{l}\text { "Top } 10 \text { leaks typically contribute more than } 80 \% \text { of emissions from } \\
\text { leaks." }\end{array}$ & p. 3 \\
\hline Shorter, 1997 & All stages & $\begin{array}{l}\text { Remote sampling } \\
\text { via tracer methods }\end{array}$ & $\begin{array}{l}\text { Repeated evidence of skewed emissions distributions: See tables } 1-7 . \\
\text { Evidence includes: top emitters of size 100x to 10,000x larger than small } \\
\text { emitters (table 9); standard deviations in excess of mean emissions rate in } \\
\text { many cases, indicating heavy-tailed distribution (table 7). }\end{array}$ & Tables 1-9 \\
\hline Trefiak 2006 & $\begin{array}{l}\text { Compressor } \\
\text { stations and } \\
\text { gas plants }\end{array}$ & $\begin{array}{l}\text { Optical } \\
\text { measurement and } \\
\text { Hi-Flow sampler }\end{array}$ & $\begin{array}{l}23 \% \text { of the } 144 \text { fugitive emissions sources were responsible for } 77 \% \text { of } \\
\text { leakage. }\end{array}$ & Fig. 2.1 \\
\hline
\end{tabular}


Unfortunately, only a small number of datasets report emissions measurements in sufficient detail to allow analysis of distributions of emissions across sources. Figure S2 plots emission distributions known by the authors at the time of review $(15,18,28)$. In Figure S2(b), the Harrison population distributions are plotted as multiples of the mean due to the different magnitudes of emissions.

Figure S3 shows the impacts of these distributions. In Figure S3(a) we plot from the NGML/Clearstone report (15) the counts of emissions sources by emissions strength. In Figure S3(b) we show the contribution to total emissions volume. As can be seen, the tail of the emissions source distribution (sources of magnitude $>10 \mathrm{MSCF} / \mathrm{d}$ ) are a small fraction of the total sources, but a large fraction of the total emissions rate.

\subsection{Challenges with uncertainty or unavailability of activity data}

Next, challenges exist if population data and AFs are inaccurate or biased. A recent study found that active well counts differ by up to 30\% in EIA and EPA datasets [p. 37 in (71)], with EPA datasets being low in well numbers. Also, numbers of wells completed for 2010 were found to differ significantly between EPA (4871 wells, of which $86 \%$ were hydraulically fractured) and industry (IHS) datasets (18542 wells, of which 61\% hydraulically fractured) [table 3 in (71)].

The use of HPDI (beginning in the 2011/2013 GHGI) as a primary data source should greatly improve the quality of activity data in the GHGI, particularly regarding wells that are hydraulically fractured. HPDI (as well as IHS and other commercial datasets), use multiple data sources - including company data - to build their well populations. Quality control for these datasets is likely to be better than state-level public datasets.

\subsection{Challenges with missing sources from inventories}

Finally, not all potential $\mathrm{CH}_{4}$ sources from $\mathrm{NG}$ use are included in the EPA GHGI as NG sources. This could cause mis-attribution of emissions. For example, emissions from the production well phase of petroleum and associated gas are not included in NG inventories, but are instead classified as petroleum emissions. Also, emissions downstream of consumer or industrial meters are not included in the NG inventory, but are instead included as stationary source or transport emissions [p. 1 in (15)]. These emissions were estimated to be potentially of significant in scale in recent work (7). Also, some sources noted above (e.g., abandoned wells or other derelict infrastructure) are not included in the inventory, an oversight of unknown importance.

There is no single unique, "correct" way to draw boundaries between industry segments. However, confusion can be created if researchers report estimated emissions rates that do not align with EPA boundary definitions when comparisons with the GHGI are then made (by the authors or others). 


\subsubsection{Current EPA GHGI methodologies and results}

The current EPA GHGI methodology was released in 2013, covering up to the 2011 calendar year. We therefore refer to this inventory as the EPA 2011/2013 inventory. Estimation methods used in this inventory are not significantly changed from the methods developed in the EPA/GRI (50) study, although many small changes have been introduced in the intervening time period (e.g., improved or updated EFs or added source categories).

The current methodology uses a three-step process. Step 1 estimates "potential" $\mathrm{CH}_{4}$ emissions. Step 2 adjusts emissions for reductions resulting from regulatory requirements and voluntary actions (e.g., those reported through the Natural Gas STAR program). Step 3 calculates the "net" emissions by subtracting emissions reductions from the potential emissions estimate.

The potential $\mathrm{CH}_{4}$ emissions estimate (Step 1) is established by combining activity data with potential emission factors for the various processes, stages and components that make up the NG system. This is largely the method developed in the EPA/GRI study. The activity data are taken from a variety of Federal, State and commercial sources. The results of the 2011/2013 EPA GHGI, estimating for calendar year $2011 \mathrm{CH}_{4}$ emissions from the NG industry, are shown in Figure S1.

The 2011/2013 EPA GHGI incorporates changes to both the EFs and AF data sources. These changes were made to reflect contemporary field practice, and more accurately characterize well populations. EFs for liquids unloading, condensate storage tanks and centrifugal compressors were updated from the 2012 GHGI.

The 2011/2013 GHGI adopted new net emission factors for liquids unloading from wells with and without plunger lifts. These EFs use data from an API/ANGA survey (71) of practices from $\sim 90,000$ wells. The $2011 / 2013$ GHGI also modifies the potential EF used for well completions and workovers with hydraulic fracturing (from 9,175 Mscf per completion/workover to 9,000 Mscf).

The 2011/2013 GHGI used new activity data. The GHGI now uses the commercial data aggregation database HPDI (40). This provides EPA with more comprehensive and upto-date data on U.S. well populations. An important change resulting from the use of HPDI data is that the number of wells hydraulically fractured has been revised upwards (from 50,434 non-associated wells in 2012 to 178,647 in 2013). The 2011/2013 GHGI also assumes a $1 \%$ yearly refracturing rate for these wells. The previous assumption was a 10\% annual refracturing rate. The increase in well count in the 2011/2013 GHGI resulted in increased emissions from hydraulic fracturing (completions and refractures).

The method for calculating emission reductions due to regulation and voluntary actions in the 2011/2013 GHGI remains unchanged. In the 2011/2013 GHGI, however, EPA assumes that $15 \%$ of U.S. hydraulically fractured well completions are subject to specific 
state regulation requiring controls. This is a downward revision resulting from the HPDI database providing a more comprehensive picture of where hydraulically fractured wells were located.

\subsubsection{Bottom-up studies performed since EPA/GRI 1996}

Several bottom-up studies have been performed since the EPA/GRI study of 1996. These studies are relatively few in number, due to the expense and challenge of making bottomup measurements and a lack of attention on $\mathrm{CH}_{4}$ emissions from $\mathrm{NG}$ systems during this time period. We note that a number of private studies likely occurred during this time period that we were unable to access.

\subsubsection{Chambers et al.}

Chambers et al. produced two reports studying emissions from NG processing plants in Canada $(14,72)$. These reports are both focused on studies performed at a small set of sweet and sour gas processing plants. The study used numerous technologies to determine leakage rates. First, leaks were visualized using a Hawk gas leak imaging camera.

Second, leakage volumes were quantified using a downwind transect with differential adsorption lidar (DIAL) technology. Lidar (sometimes described as "Light Detection and Ranging") technology is a backscatter-based technology, wherein laser light of a given wavelength is reflected back to the sensor by the substance of interest, and the time to return to the sensor is recorded to estimate distance to the substance. By utilizing two light wavelengths, one strongly absorbed by the species of interest, DIAL allows the calculation of gas concentration as a function of distance from the DIAL source. DIAL therefore produces a 2-dimensional "slice" or transect of gas concentrations across a plane downwind from the facility. When coupled with simultaneous wind measurements at the same site, the mass flux of emissions can be estimated across the plane.

Chambers et al. found that emissions from gas plants were generally higher than the predicted quantities generated using the CAPP (Canadian Association of Petroleum Producers) detailed emissions estimation methods.

\subsubsection{Harrison et al.}

Harrison et al. (18) produced a draft report for improving default emissions factors for compressors and other equipment under an EPA contract. The key focus of the study was on reciprocating and centrifugal compressors, including transmission, boosting/gathering and gas processing compressors. A smaller sampling effort including valves and flanges was also performed.

The Harrison et al. team first identified leaking components using a FLIR infrared camera. The volume of gas emissions from these leaking components was then quantified 
using a Hi-Flow sampler. The Hi-Flow sampler draws a large volume of air from the vicinity of the leak, ensuring that the total volume of the leak is drawn into the device. The concentration of gas measured in the flow through the device, coupled with the flow rate, provides an estimate of gas emissions rate ( $\pm 10 \%$ accuracy).

\subsubsection{Clearstone}

The Clearstone study of $2002(15,81)$ was prepared for the Gas Technology Institute and the EPA. It focused on emissions at gas processing plants, examining four processing plants in a detailed device-level sampling effort. Over 100,000 individual sources were sampled as part of the study.

The Clearstone methodology surveyed all individual sources using bubble tests, portable hydrocarbon gas detectors, or ultrasonic leak detectors. The bubble test was the most commonly used test, due to rapid, low-cost application. Devices that were determined to be leaking ( $\sim 2.6 \%$ of tested components) were then tested with either the Hi-Flow sampler (82) (if the leak volume was not larger than device capacity) or through bagging and direct measurement if the leak volume was larger than Hi-Flow capacity.

The results from the Clearstone study found that emissions factors were generally higher than those defined under EPA/GRI (50) and that a very large number of the leaks subject to direct measurement would be cost-effective to repair.

\subsubsection{NGML et al.}

In 2006, the National Gas Machinery Laboratory partnered with Clearstone Engineering Ltd. and Innovative Environmental Solutions to release a Phase II report (21), building off of the original Clearstone 2002 report. The Phase II project studied five more gas plants, in addition to examining well sites and gathering compressor stations.

In this study, nearly 75,000 individual components were examined. Results were similar to the first phase study: $\sim 2.2 \%$ of the components were found to be leaking (i.e., had a screening concentration measured above $10,000 \mathrm{ppm}$ ). The methodology for the Phase II study was similar to Phase I, except for the addition of an IR camera method to perform rapid screening of leaking components.

Similarly to the Phase I study, the Phase II study found that EPA/GRI EFs, on balance, underestimated emissions from gas plants. They also reinforced the finding from Phase I that the vast majority of leaks are able to be repaired at no net cost to operators.

\subsubsection{GTI}

In 2009, the Gas Technology Institute performed a study on distribution system emissions (16). The GTI study focused on meters and metering/regulation stations. 
Residential, commercial, and industrial sites were studied. Sample sizes were modest to large, with 2400 residential meters sampled, 393 commercial meters, and 46 industrial meters. Qualitative assessment of leaks was performed using bubble tests, portable pas detectors and the FLIR GasFindIR camera. After leaking components were found, quantitative mass flux estimates were generated with a Hi-Flow sampler.

GTI found that residential meter emissions factors were lower than previous EPA/GRI Tier 3 method, while commercial and residential meters had far higher emissions than previous EFs.

\subsubsection{Allen et al.}

Allen et al. (26) performed measurements of production-phase operations including: completions flowback during hydraulic fracturing operations, chemical pumps, pneumatic controllers, liquids unloading (with and without plunger lifts) well workovers, and other equipment leaks. Notably, Allen et al. devised novel containment strategies to directly measure emissions from hydraulic fracturing flowback (both with and without reduced emissions completions technologies in place), allowing much improved understanding of both potential and net (after mitigation) emissions from completions operations. For smaller sources Allen et al. used initial scans with infrared cameras, followed by Hi-Flow sampling to quantify flux.

In aggregate, Allen et al. found generally good agreement between EPA productionphase inventoried emissions and their estimates. However, their source-specific results differed significantly from EPA: their emissions during hydraulic fracturing were much lower than EPA estimates, while emissions from pumps, controllers, and other equipment leaks were higher. Importantly, Allen et al. note that liquids unloading present a potentially large and highly variable source of emissions, which require additional study.

\subsection{Alignment between bottom-up and top-down studies: Attribution and system boundaries}

A key challenge in aligning the results of top-down and bottom-up studies is that the boundaries of analysis can be quite different: what is observed in the atmosphere does not correspond or cohere to boundaries that are placed on an analysis performed for an inventory or life cycle assessment (LCA).

To illustrate the problem, consider the following case: assume an ideal atmospheric experiment that can correctly measure the $\mathrm{CH}_{4}$ emissions from oil and gas operations and distinguish these emissions from not only biogenic sources, but also other anthropogenic $\mathrm{CH}_{4}$ sources such as coal mines. Aligning the results from such a study to EPA estimates of $\mathrm{NG}$ emissions would still be challenged for the following reasons:

1. EPA definitions of the $\mathrm{NG}$ system do not include emissions of $\mathrm{CH}_{4}$ from oil production operations. That is, if a well is classified as an "oil well", its 
emissions of $\mathrm{CH}_{4}$ are counted as petroleum sector emissions, even though the associated gas from that well will enter (possibly after some local processing) the NG sector as per EPA definitions.

2. EPA definitions of emissions from the NG system do not debit any of the emissions from NG operations according to the fraction of co-produced liquids. That is, if a well produces NG condensate that is blended into the liquid fuel supply, no share of the $\mathrm{CH}_{4}$ emitted from the "gas" well or processing equipment is allocated to the petroleum sector, even though a (potentially significant) fraction of the energy produced by the well would end up as products commonly conceived of as "petroleum" products.

This problem of allocation of emissions to "co-products" is a general one in environmental assessment, and has been a topic of interest and research in the life cycle assessment literature for many years. There is not a generally agreed-upon "correct" method for performing such allocation.

\subsection{Dedication}

We dedicate this article to George P. Mitchell. He was an innovator in recovering vented and stranded natural gas, and as a petroleum engineer and geologist, Mitchell was credited with leading development of hydraulic fracturing techniques.

George Mitchell was a dedicated and early supporter of the use of science to advance sustainability. He realized that there were finite energy resources and raw materials for our world. This understanding stimulated his sponsorship of the 1970s Club of Rome study, The Limits to Growth. He subsequently founded the Houston Advanced Research Center (HARC), which focuses on critical regional issues such as clean energy, air, and water. More recently, the Mitchells underwrote the National Academies' landmark report Our Common Journey: A Transition Toward Sustainability. 


\subsection{Advisory and Financial Disclosures}

Financial: Significant financial interest (equity holdings or stock options) in any corporate entity dealing with the material or the subject matter of this contribution. Please disclose the entity and the nature and amount of the holding:

\section{A.R. Brandt}

No individual stocks in oil and gas companies. All financial interests in the oil and gas sector are contained in retirement accounts in broad (non-sector specific) index funds.

E.A. Kort

No individual stocks in oil \& gas companies. All financial interests in oil and gas sector are via broad (non sector specific) index funds.

F. O'Sullivan

I do not hold any individual oil, gas or other energy sector securities. I passively hold mutual fund investments in index funds including energy-sector index funds.

D. Arent

Inherited mineral rights, not "significant". All other financial interests in blind/broad mutual funds.

D. Eardley

I have no stocks or bonds in the energy sector, except as part of broadly index-based retirement accounts (Fidelity, TIAA/CREF).

Paid Consulting: Within the last 3 years, receipt of consulting fees, honoraria, speaking fees, or expert testimony fees from entities that have a financial interest in the results and materials of this study. Please enumerate. I have a paid consulting relationship, described as:
A.R. Brandt
I have received pay as a consultant in the last 3 years for the following organizations: International Council on Clean Transportation (ICCT), European Commission: Directorate General - Climate, UK Department for International Development (DFID).
F. O'Sullivan
In the last 3 years, have participated in sponsored research supported by the following groups: Accenture, BP, Cyprus Institute, Enel, MIT Energy Initiative Seed Fund Program, NREL/Joint Institute for Strategic Energy Analysis, The Sloan Foundation, Weatherford International. In the last 3 years, I have received modest speaking and review honoraria from the following organizations: $B P, B$-Tec Foundation, Cambridge Energy Research Associates/IHS, Enagas, Environmental Defense Fund, EPRI, IEA 


\title{
S.M. Jordaan
}

I was employed at the Electric Power Research Institute as a Project Manager from April 2012-April 2013. At EPRI, I was involved in the publication of a report on shale gas production released in 2013, which was funded by 10 companies in the electric sector. I consulted British Petroleum (BP) on technology innovation and water use of unconventional fuels for \$2000, a one time fee for a presentation at a workshop in July 2013. The Energy Technology Innovation Policy Research group at Harvard (where I was a fellow from 2011-2012) receives funding from (in part) from BP. I have been engaged with NRDC most recently (December 2013) in a workshop on air and water impacts of unconventional gas. Travel and lodging were provided, but no speaking fees or honoraria were involved.

\section{N.J. Brown}

I consulted for API with a group of scholars to write a report on Policy relevant background ozone. I was paid a modest stipend to serve on an EPA advisory committee and a search committee.

Management/Advisory affiliations: Within the last 3 years, status as an officer, a member of the Board, or a member of an Advisory Committee of any entity engaged in activity related to the subject matter of this contribution. Please disclose the nature of these relationships and the financial arrangements. I have a management/advisory relationship, described as:

A.R. Brandt

I am currently serving on the Science Advisory Board for a study led by the California Council on Science and Technology that is examining environmental impacts of unconventional oil production technologies.

D. Arent

I served on National Petroleum Council NARD Study Policy Subcommittee I serve on committee to advise USGCRP at National Academy

\author{
N.J. Brown \\ I serve on a technical advisory committee for the DOE for Unconventional Resources. I \\ receive no financial support except for travel expenses. I also serve on advisory \\ committees for the EPA, and I receive a modest stipend for this along with travel \\ expenses. \\ D. Eardley \\ Member, NAS/NRC panel on Inertial Confinement Fusion Energy Targets. Member, Joint \\ LANL/LLNL Mission Committee. Member, JASON Study Group, U.S. Department of \\ Defense and Department of Energy Member, Sandia National Lab External Review Panel \\ for High Energy Density Science. I receive or have received fees for the above.
}


Advisory and Funding

Other Funding Sources: Additional funding sources not noted in the manuscript are:

\begin{abstract}
A.R. Brandt
In the last 3 years, I have participated in sponsored research paid for by the following groups: California Air Resources Board; Argonne National Laboratory; Carnegie Endowment for Global Peace; Global Climate and Energy Project; Institute for Integrated Economic Research.
\end{abstract}

In the last 3 years, my students (PhD and MS) have received fellowship funding from the following sources: Stanford School of Earth Sciences Graduate Fellowship; Stanford Graduate Fellowship (University-wide fellowship); National Science Foundation (NSF); Chevron Inc. (through Stanford School of Earth Sciences); Illich-Sadowsky Stanford Interdisciplinary Graduate Fellowship (University-wide fellowship); Stanford University Undergraduate Summer Research Fellowship.

G. Pétron

GP's contribution to this manuscript was supported by NOAA and the NSF AirWaterGas Sustainability Research Network.

D. Eardley

I have received honoraria for participation in workshops at the Center for Urban Science and Progress, New York University. 


\section{Supplemental Figures}
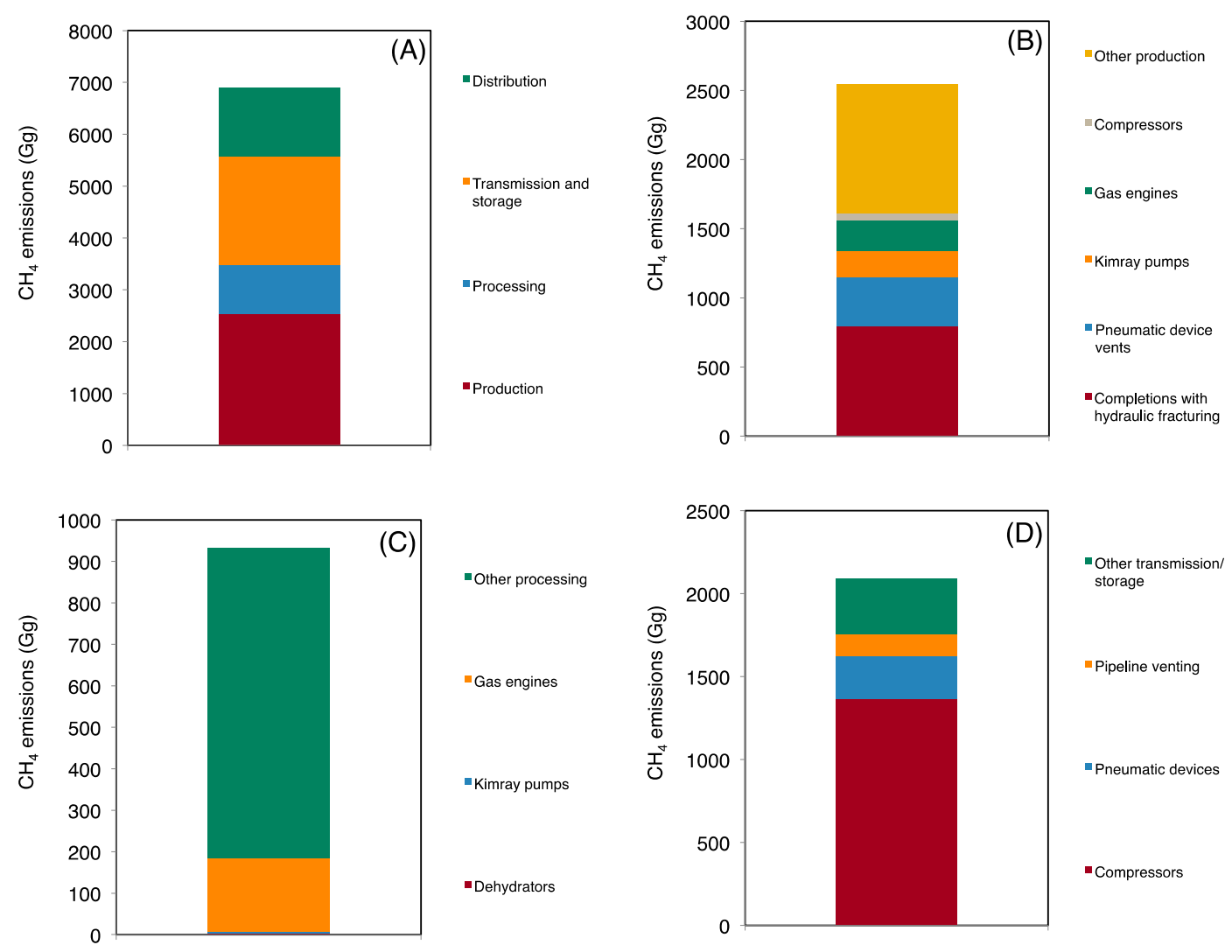

Fig. S1. $\mathrm{CH}_{4}$ emissions from EPA 2011 inventory for the NG sector. (A) Total breakdown between four process stages. Sector specific breakdown for Production (B), Processing (C) and Transmission and Storage (D). Source: [table A-138 (32)]. 


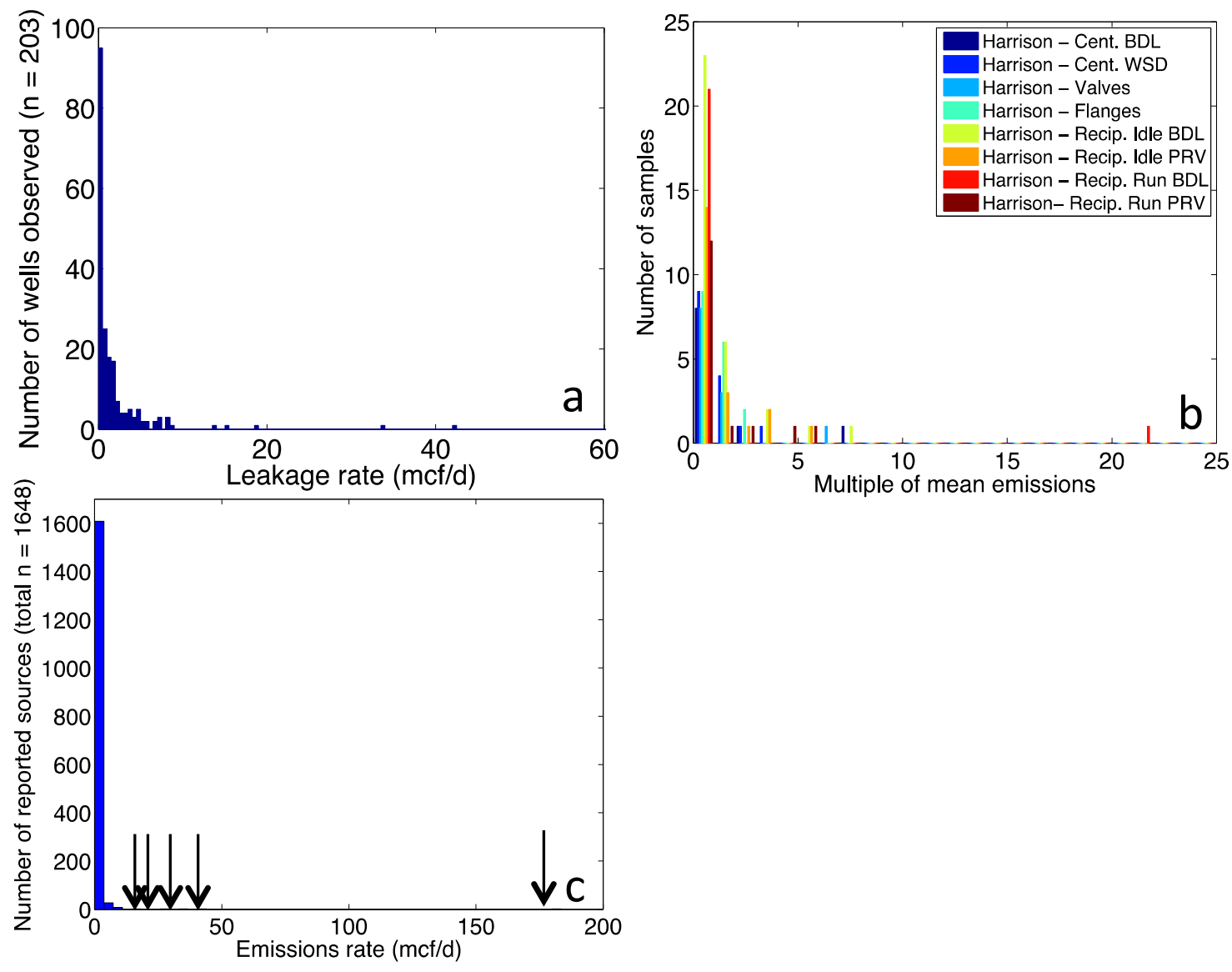

Fig. S2. (a) Observed distribution of leakage rates across 203 wells reported by Alvarez et al. (28). Original data from a study in Fort Worth region (83). (b) Observations of leakage rates by type of equipment and source from the Harrison et al. study (13). In the Harrison plot, emissions for each group of equipment are expressed as multiples of the mean emissions for that group. (c) Distribution of emissions across $\sim 1600$ extracted emissions rates from the Clearstone et al. study [Appendix I in (16)] Marked with black arrows are single sources that are unable to be seen due to the axis scale: high emitters at $10-50 \mathrm{mcf} / \mathrm{d}$ and one very high emitter above $150 \mathrm{mcf} / \mathrm{d}$. 

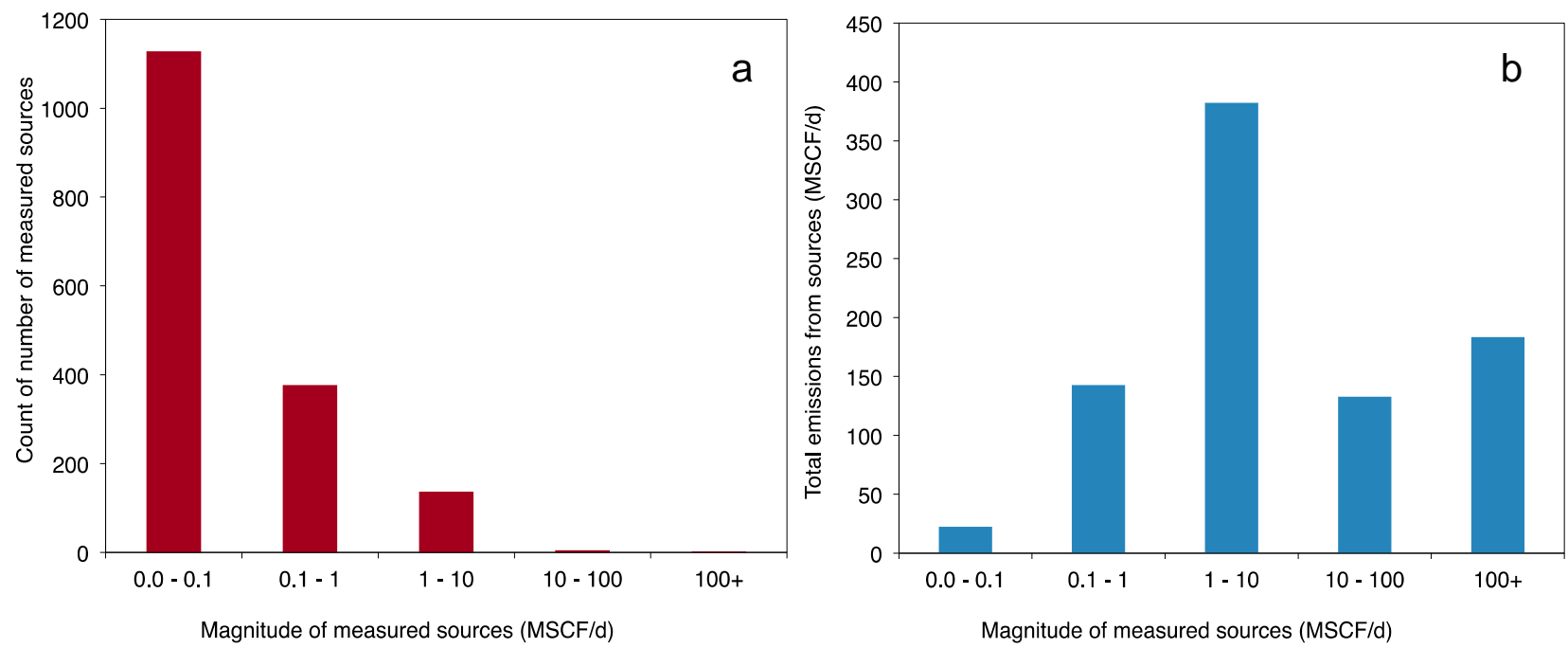

Fig. S3. Comparison of (a) the numbers of counts of sources by emissions strength, and (b) the volume of emissions by emissions strength for the NGML/Clearstone dataset (16). A small number of emissions sources in the tail of the emissions distribution $(10+\mathrm{MSCF} / \mathrm{d})$ account for a large fraction of the total emissions. 


\section{References}

1. A. Karion, C. Sweeney, G. Pétron, G. Frost, R. Michael Hardesty, J. Kofler, B. R. Miller, T. Newberger, S. Wolter, R. Banta, A. Brewer, E. Dlugokencky, P. Lang, S. A. Montzka, R. Schnell, P. Tans, M. Trainer, R. Zamora, S. Conley, Methane emissions estimate from airborne measurements over a western United States natural gas field. Geophys. Res. Lett. 40, 4393-4397 (2013). doi:10.1002/grl.50811

2. J. Peischl et al., Quantifying sources of methane using light alkanes in the Los Angeles basin, California. J. Geophys. Res. 118, 4974 (2013).

3. G. Pétron, G. Frost, B. R. Miller, A. I. Hirsch, S. A. Montzka, A. Karion, M. Trainer, C. Sweeney, A. E. Andrews, L. Miller, J. Kofler, A. Bar-Ilan, E. J. Dlugokencky, L. Patrick, C. T. Moore, Jr., T. B. Ryerson, C. Siso, W. Kolodzey, P. M. Lang, T. Conway, P. Novelli, K. Masarie, B. Hall, D. Guenther, D. Kitzis, J. Miller, D. Welsh, D. Wolfe, W. Neff, P. Tans, Hydrocarbon emissions characterization in the Colorado Front Range: A pilot study. J. Geophys. Res. 117, (D4), D04304 (2012). doi:10.1029/2011JD016360

4. E. G. Nisbet, E. J. Dlugokencky, P. Bousquet, Atmospheric science. Methane on the rise - again. Science 343, 493-495 (2014). doi:10.1126/science.1247828 Medline

5. E. A. Kort, J. Eluszkiewicz, B. B. Stephens, J. B. Miller, C. Gerbig, T. Nehrkorn, B. C. Daube, J. O. Kaplan, S. Houweling, S. C. Wofsy, Emissions of $\mathrm{CH}_{4}$ and $\mathrm{N}_{2} \mathrm{O}$ over the United States and Canada based on a receptor-oriented modeling framework and COBRA-NA atmospheric observations. Geophys. Res. Lett. 35, L18808 (2008). doi:10.1029/2008GL034031

6. S. M. Miller, S. C. Wofsy, A. M. Michalak, E. A. Kort, A. E. Andrews, S. C. Biraud, E. J. Dlugokencky, J. Eluszkiewicz, M. L. Fischer, G. Janssens-Maenhout, B. R. Miller, J. B. Miller, S. A. Montzka, T. Nehrkorn, C. Sweeney, Anthropogenic emissions of methane in the United States. Proc. Natl. Acad. Sci. U.S.A. 110, 20018 20022 (2013). doi:10.1073/pnas.1314392110 Medline

7. P. O. Wennberg, W. Mui, D. Wunch, E. A. Kort, D. R. Blake, E. L. Atlas, G. W. Santoni, S. C. Wofsy, G. S. Diskin, S. Jeong, M. L. Fischer, On the sources of methane to the Los Angeles atmosphere. Environ. Sci. Technol. 46, 9282-9289 (2012). doi:10.1021/es301138y Medline

8. Y. Xiao, J. A. Logan, D. J. Jacob, R. C. Hudman, R. Yantosca, D. R. Blake, Global budget of ethane and regional constraints on U.S. sources. J. Geophys. Res. 113, (D21), D21306 (2008). doi:10.1029/2007JD009415

9. A. S. Katzenstein, L. A. Doezema, I. J. Simpson, D. R. Blake, F. S. Rowland, Extensive regional atmospheric hydrocarbon pollution in the southwestern United States. Proc. Natl. Acad. Sci. U.S.A. 100, 11975-11979 (2003). doi:10.1073/pnas. 1635258100 Medline

10. Y.-K. Hsu, T. VanCuren, S. Park, C. Jakober, J. Herner, M. FitzGibbon, D. R. Blake, D. D. Parrish, Methane emissions inventory verification in southern California. Atmos. Environ. 44, 1-7 (2010). doi:10.1016/j.atmosenv.2009.10.002 
11. A. Townsend-Small, S. C. Tyler, D. E. Pataki, X. Xu, L. E. Christensen, Isotopic measurements of atmospheric methane in Los Angeles, California, USA: Influence of "fugitive" fossil fuel emissions. J. Geophys. Res. 117, (D7), D07308 (2012). doi:10.1029/2011JD016826

12. D. Wunch, P. O. Wennberg, G. C. Toon, G. Keppel-Aleks, Y. G. Yavin, Emissions of greenhouse gases from a North American megacity. Geophys. Res. Lett. 36, n/a (2009). doi:10.1029/2009GL039825

13. J. S. Wang, J. A. Logan, M. B. McElroy, B. N. Duncan, I. A. Megretskaia, R. M. Yantosca, A 3-D model analysis of the slowdown and interannual variability in the methane growth rate from 1988 to 1997. Global Biogeochem. Cycles 18, 361 (2004). doi:10.1029/2003GB002180

14. A. Chambers, Optical Measurement Technology for Fugitive Emissions from Upstream Oil and Gas Facilities (Alberta Research Council, Edmonton, AB, 2004).

15. Clearstone Engineering, Identification and Evaluation of Opportunities to Reduce methane Losses at Four Gas Processing Plants (Gas Technology Institute, Des Plaines, IL, 2002).

16. Innovative Environmental Solutions, Field Measurement Program to Improve Uncertainties for Key Greenhouse Gas Emissions Factors for Distribution Sources (Gas Technology Institute, Des Plaines, IL, 2009).

17. EPA, "Inventory of U.S. greenhouse gas emissions and sinks: 1990-2011" (EPA, 2013).

18. M. R. Harrison et al., Natural Gas Industry Methane Emissions Factor Improvement Study (EPA, 2011).

19. K. E. Hummel et al., Methane Emissions from the Natural Gas Industry, vol. 8, Equipment Leaks (EPA, 1996).

20. H. J. Williamson et al., Methane Emissions from the Natural Gas Industry, vol. 4, Statistical Methodology (EPA, 1996).

21. National Gas Machinery Laboratory, Clearstone Engineering, Innovative Environmental Solutions, Cost-Effective Directed Inspection and Maintenance Control Opportunities at Five Gas Processing Plants and Upstream Gathering Compressor Stations and Well Sites (EPA, 2006).

22. Office of Inspector General, EPA, EPA Needs to Improve Air Emissions Data for the Oil and Natural Gas Production Sector (EPA, 2013).

23. EPA, Fed. Regist. 77(159), 49490 (16 August 2012); 40 Code of Federal Regulations, Parts 60 and 63.

24. EPA, Greenhouse Gas Reporting Program, subpart W, Petroleum and Natural Gas Systems (EPA, 2013). 
25. M. A. Levi, Comment on "Hydrocarbon emissions characterization in the Colorado Front Range: A pilot study" by Gabrielle Pétron et al. J. Geophys. Res. 117, (D21), 16 (2012). doi:10.1029/2012JD017686

26. D. T. Allen, V. M. Torres, J. Thomas, D. W. Sullivan, M. Harrison, A. Hendler, S. C. Herndon, C. E. Kolb, M. P. Fraser, A. D. Hill, B. K. Lamb, J. Miskimins, R. F. Sawyer, J. H. Seinfeld, Measurements of methane emissions at natural gas production sites in the United States. Proc. Natl. Acad. Sci. U.S.A. 110, 17768-17773 (2013). doi:10.1073/pnas.1304880110 Medline

27. C. L. Weber, C. Clavin, Life cycle carbon footprint of shale gas: review of evidence and implications. Environ. Sci. Technol. 46, 5688-5695 (2012). doi:10.1021/es300375n Medline

28. R. A. Alvarez, S. W. Pacala, J. J. Winebrake, W. L. Chameides, S. P. Hamburg, Greater focus needed on methane leakage from natural gas infrastructure. Proc. Natl. Acad. Sci. U.S.A. 109, 6435-6440 (2012). doi:10.1073/pnas.1202407109 Medline

29. Environmental Defense Fund, Natural gas: EDF is fighting for tough rules and enforcement (EDF, 2013); www.edf.org/climate/natural-gas.

30. Energy Information Administration (EIA, Washington, DC, 2013), www.eia.gov/naturalgas/

31. EPA, "Inventory of U.S. Greenhouse Gas Emissions and Sinks: 1990-2011. Annex 3: Methodological descriptions for additional source or sink categories" (EPA, 2013).

32. G. Pétron, G. J. Frost, M. K. Trainer, B. R. Miller, E. J. Dlugokencky, P. Tans, Reply to comment on "Hydrocarbon emissions characterization in the Colorado Front Range - A pilot study" by Michael A. Levi. J. Geophys. Res. 118, 236-242 (2013). doi:10.1029/2012JD018487

33. T. A. McAllister, K. A. Beauchemin, S. M. McGinn, X. Hao, P. H. Robinson, Greenhouse gases in animal agriculture-Finding a balance between food production and emissions. Anim. Feed Sci. Technol. 166-167, 1-6 (2011). doi:10.1016/j.anifeedsci.2011.04.057

34. EPA, "Methane and nitrous oxide emissions from natural sources" (EPA, 2010).

35. G. Etiope, K. Lassey, R. W. Klusman, E. Boschi, Reappraisal of the fossil methane budget and related emission from geologic sources. Geophys. Res. Lett. 35, L09307 (2008). doi:10.1029/2008GL033623

36. EIA, "U.S. Crude oil, natural gas, and dry exploratory and development wells drilled" (EIA, Washington, DC, 2013).

37. H. F. Williamson, The American Petroleum Industry, 1899-1959, the Age of Energy. (Northwestern Univ. Press, Evanston, IL, 1963).

38. R. Arnold, W. J. Kemnitzer, Petroleum in the United States and Its Possessions (Harper \& Brothers Publishers, New York, 1931). 
39. EIA, "Distribution of wells by production rate bracket" (EIA, Washington, DC, 2010).

40. HPDI, "HPDI oil and gas production dataset" (HPDI, Austin, TX, 2013).

41. F. O'Sullivan, S. Paltsev, Shale gas production: Potential versus actual greenhouse gas emissions. Environ. Res. Lett. 7, 044030 (2012). doi:10.1088/1748$\underline{9326 / 7 / 4 / 044030}$

42. Division of Oil, Gas and Geothermal Resources, "2008 Annual Report of the Oil and Gas Supervisor" (DOGGR, California Department of Conservation, Sacramento, CA, 2009).

43. R. W. Howarth, R. Santoro, A. Ingraffea, Methane and the greenhouse-gas footprint of natural gas from shale formations. Clim. Change 106, 679-690 (2011). doi:10.1007/s10584-011-0061-5

44. R. Howarth, R. Santoro, A. Ingraffea, Venting and leaking of methane from shale gas development: response to Cathles et al. Clim. Change 113, 537-549 (2012). doi:10.1007/s10584-012-0401-0

45. A. Karion, G. Pétron, C. Sweeney, in U.S. EPA Stakeholder Workshop on Natural Gas in the Inventory of U.S. Greenhouse Gas Emissions and Sinks, Washington, DC, 13 to 14 September 2012 (EPA, 2012).

46. D. T. Shindell, G. Faluvegi, D. M. Koch, G. A. Schmidt, N. Unger, S. E. Bauer, Improved attribution of climate forcing to emissions. Science 326, 716-718 (2009). doi:10.1126/science. 1174760 Medline

47. D. Blake, V. H. Woo, S. C. Tyler, F. S. Rowland, Methane concentrations and source strengths in urban locations. Geophys. Res. Lett. 11, 1211-1214 (1984). doi:10.1029/GL011i012p01211

48. K. L. Mays, P. B. Shepson, B. H. Stirm, A. Karion, C. Sweeney, K. R. Gurney, Aircraft-based measurements of the carbon footprint of Indianapolis. Environ. Sci. Technol. 43, 7816-7823 (2009). doi:10.1021/es901326b Medline

49. J. H. Shorter, J. B. Mcmanus, C. E. Kolb, E. J. Allwine, B. K. Lamb, B. W. Mosher, R. C. Harriss, U. Partchatka, H. Fischer, G. W. Harris, P. J. Crutzen, H.-J. Karbach, Methane emission measurments in urban areas in Eastern Germany. J. Atmos. Chem. 24, 121-140 (1996). doi:10.1007/BF00162407

50. M. R. Harrison, L. M. Campbell, T. M. Shires, R. M. Cowgill, Methane Emissions from the Natural Gas Industry, vol. 1, Executive Summary [EPA Global Reporting Initiative (GRI), 1996].

51. J. B. Gilman, B. M. Lerner, W. C. Kuster, J. A. de Gouw, Source signature of volatile organic compounds from oil and natural gas operations in northeastern Colorado. Environ. Sci. Technol. 47, 1297-1305 (2013). doi:10.1021/es4036978 Medline

52. J. H. Shorter, J. B. McManus, C. E. Kolb, E. J. Allwine, B. K. Lamb, B. W. Mosher, R. C. Harriss, T. Howard, R. A. Lott, Collection of Leakage Statistics in the Natural 
Gas System by Tracer Methods. Environ. Sci. Technol. 31, 2012-2019 (1997). doi:10.1021/es9608095

53. B. K. Lamb, J. B. McManus, J. H. Shorter, C. E. Kolb, B. Mosher, R. C. Harriss, E. Allwine, D. Blaha, T. Howard, A. Guenther, R. A. Lott, R. Siverson, H. Westburg, P. Zimmerman, Development of atmospheric tracer methods to measure methane emissions from natural gas facilities and urban areas. Environ. Sci. Technol. 29, 1468-1479 (1995). doi:10.1021/es00006a007 Medline

54. H. El-Houjeiri, A. Brandt, "Oil Production Greenhouse Gas Emissions Estimator (OPGEE) v1.0: User guide \& Technical documentation” (Stanford University, for California Air Resources Board, Stanford, CA, 2012).

55. J. Logan, G. Heath, J. Macknick, E. Paranhos, W. Boyd, Natural Gas and the Transformation of the U.S. Energy Sector: Electricity (Joint Institute for Strategic Energy Analysis, 2012).

56. A. Gelman, J. B. Carlin, H. S. Stern, D. B. Rubin, Baysesian Data Analysis. (Chapman and Hall/CRC, ed. 2, 2004).

57. D. A. Kirchgessner, R. A. Lott, R. M. Cowgill, M. R. Harrison, T. M. Shires, Estimate of methane emissions from the U.S. natural gas industry. Chemosphere 35, 1365-1390 (1997). doi:10.1016/S0045-6535(97)00236-1 Medline

58. L. M. Campbell, M. V. Campbell, D. L. Epperson, Methane Emissions from the Natural Gas Industry, vol. 9, Underground Pipelines (EPA/GRI, 1996).

59. L. M. Campbell, B. E. Stapper, Methane Emissions from the Natural Gas Industry, vol. 10, Metering and Pressure Regulating Stations in Natural Gas Transmission and Distribution (EPA/GRI, 1996).

60. M. R. Harrison, L. M. Campbell, T. M. Shires, R. M. Cowgill, Methane Emissions from the Natural Gas Industry, vol. 2, Technical Report (EPA/GRI, 1996).

61. M. R. Harrison, H. J. Williamson, L. M. Campbell, Methane Emissions from the Natural Gas Industry, vol. 3, General Methodology (EPA/GRI, 1996).

62. D. Myers, Methane Emissions from the Natural Gas Industry, vol. 14, Glycol Dehydrators (EPA/GRI, 1996).

63. D. B. Myers, M. R. Harrison, Methane Emissions from the Natural Gas Industry, vol. 15, Gas-Assisted Glycol Pumps (EPA/GRI, 1996).

64. T. M. Shires, Methane Emissions from the Natural Gas Industry, vol. 13, Chemical Injection Pumps (EPA/GRI, 1996).

65. T. M. Shires, M. R. Harrison, Methane Emissions from the Natural Gas Industry, vol. 6, Vented and Combustion Source Summary (EPA/GRI, 1996).

66. T. M. Shires, M. R. Harrison, Methane Emissions from the Natural Gas Industry, vol. 7, Blow and Purge Activities (EPA/GRI, 1996).

67. T. M. Shires, M. R. Harrison, Methane Emissions from the Natural Gas Industry, vol. 12, Pneumatic Devices (EPA/GRI, 1996). 
68. B. E. Stapper, Methane Emissions from the Natural Gas Industry, vol. 5, Activity Factors (EPA/GRI, 1996).

69. C. J. Stapper, Methane Emissions from the Natural Gas Industry, vol. 11, Compressor Driver Exhaust (EPA/GRI, 1996).

70. IPCC, "IPCC Guidelines for National Greenhouse Gas Inventories" (National Greenhouse Gas Inventories Programme, Intergovernmental Panel on Climate Change, 2006).

71. T. Shires, M. Lev-On, Characterizing Pivotal Sources of Methane Emissions from Unconventional Natural Gas Production: Summary and Analysis of API and ANGA Survey Responses (American Petroleum Institute, America's Natural Gas Alliance, Washington, DC, 2012).

72. A. K. Chambers, M. Strosher, T. Wootton, J. Moncrieff, P. McCready, Direct measurements of fugitive emissions from natural gas plants and the comparison with emission factor estimates. J. Air Waste Manage. Assoc. 58, 1047-1056 (2006). doi:10.3155/1047-3289.58.8.1047

73. J. Cormack, in Energy Management Workshop for Upstream and Midstream Operations: Increasing Revenue through Process Optimization \& Methane Emissions Reduction. (Global Methane Initiative, Calgary, Alberta, Canada, 2007).

74. D. Picard, in Modern Technologies of Detection and Elimination of Methane Leakages from Natural Gas Systems (Akademgorodok, Russia, 2005).

75. T. Trefiak, "Pilot study: Optical leak detection and measurement" (ConocoPhillips, 2006).

76. Star Environmental, "Fugitive hydrocarbon emissions from oil and gas production operations" (American Petroleum Institute, 1993).

77. Star Environmental, " Fugitive hydrocarbon emissions: Eastern gas wells" (Gas Research Institute, 1995).

78. Indaco Air Quality Services, "Leak rate measurements for natural gas customer meters" (Gas Research Institute, Des Plaines, IL, 1994).

79. Indaco Air Quality Services, "Leak rate measurements at us natural gas transmission compressor stations" (Gas Research Institute, Des Plaines, IL, 1996).

80. Star Environmental, "Fugitive methane emissions, customer meter sets" (Gas Research Institute, Des Plaines, IL, 1995).

81. R. Fernandez, D. Robinson, V. Aggarwal, Study comparison reveals methaneemissions reduction opportunities in gas processing. Oil Gas J. 103 ( ), 22 (2005).

82. Bacharach Inc., "Hi Flow sampler: For natural gas leak rate measurement" (Bacharach, New Kensington, PA, 2013).

83. Eastern Research Group, Sage Environmental Consulting, "City of Fort Worth Natural Gas Air Quality Study" (City of Fort Worth, TX, 2011). 